\title{
The Role of Food Web Interactions in Multispecies Fisheries Management: Bio-economic Analysis of Salmon, Herring and Grey Seal in the Northern Baltic Sea
}

\author{
Tin-Yu Lai ${ }^{1,2,5}$ (D) Marko Lindroos ${ }^{1,2} \cdot$ Lone Grønbæk $^{3} \cdot$ Atso Romakkaniemi $^{4}$
}

Accepted: 23 May 2021 / Published online: 26 June 2021

(c) The Author(s) 2021

\begin{abstract}
Multispecies bio-economic models are useful tools to give insights into ecosystem thinking and ecosystem-based management. This paper developed an age-structured multispecies bio-economic model that includes the food web relations of the grey seal, salmon, and herring, along with salmon and herring fisheries in the Baltic Sea. The results show that the increasing seal population influences salmon fisheries and stock, but the impacts on the harvest are stronger than on the stock if the targeted management policies are obeyed. If seal population growth and a low herring stock occur simultaneously, the salmon harvest could face a serious threat. In addition, scenarios of the multispecies management approach in this paper reveal a benefit that our model can evaluate the performance of different fisheries with identical or different management strategies simultaneously. The results show the most profitable scenario is that both fisheries pursuit aggregated profits and reveal a trade-off between herring fisheries and salmon fisheries. Our model indicates that the herring harvest level and the approaches to managing herring fisheries can influence the performance of salmon fisheries. The study also demonstrates a way to develop a multispecies bio-economic model that includes both migratory fish and mammalian predators.
\end{abstract}

Keywords Bio-economic modeling · Dynamic optimization · Food web interaction · Grey seal (Halichoerus grypus) $\cdot$ Herring $($ Clupea harengus) $\cdot$ Multiobjective $\cdot$ Multispecies management $\cdot$ Salmon (Salmo salar)

This paper has not been submitted elsewhere in identical or similar form, nor will it be during the first three months after its submission to the Publisher.

Tin-Yu Lai

tin-yu.lai@helsinki.fi

1 Department of Economics and Management, University of Helsinki, P.O. Box 27, 00014 Helsinki, Finland

2 Helsinki Institute of Sustainability Science (HELSUS), Helsinki, Finland

3 Department of Business and Economics, University of Southern Denmark, 5230 Odense M, Denmark

$4 \quad$ Natural Resources Institute Finland (LUKE), 90014 Oulu, Finland

5 Marine Research Centre, Finnish Environment Institute (SYKE), Latokartanonkaari 11, 00790 Helsinki, Finland 


\section{Abbreviations}

$\begin{array}{ll}\text { EBFM } & \text { Ecosystem-based fishery management } \\ \text { EBM } & \text { Ecosystem-based management } \\ \text { MSFD } & \text { European Marine Strategy Framework Directive } \\ \text { MSY } & \text { Maximum sustainable yield } \\ \text { MEY } & \text { Maximum economic yield } \\ \text { MH policy } & \text { Policy to maximize long-term harvest } \\ \text { NPV } & \text { Net present value } \\ \text { SSB } & \text { Spawning stock biomass } \\ \text { TSB } & \text { Total stock biomass }\end{array}$

\section{Introduction}

Ecosystem-based fishery management (EBFM) and ecosystem-based management (EBM) have been recommended for managing marine ecosystems to overcome the ineffectiveness and limitations of single species or single-sector management that has led to issues such as overexploitation, destruction of marine habitats and ecosystem functions, and conflicts among stakeholders (Fogarty 2014; Link 2002; Long et al. 2015; Nguyen 2012; Pikitch et al. 2004). On the European level, EBM has been adopted by the European Marine Strategy Framework Directive (MSFD) as the approach through which marine waters can achieve "good environmental status" (European Union 2008). Both EBFM and EBM are holistic approaches that involve the interactions among physical, biogeochemical, ecological and social-economic systems (Long et al. 2015; Marasco et al. 2007; Patrick and Link 2015).

Ecological-economic models or bio-economic models can provide insights for EBFM and EBM. Such models are useful for understanding the feedback, interactions, and tradeoffs between the ecological and social-economic systems; therefore, they can support management decisions that jointly consider different systems (Doyen et al. 2013; Francis et al. 2007; Nguyen 2012; Nielsen et al. 2018). Furthermore, within the ecological system, food webs are considered in EBFM or EBM (Link 2002; Marasco et al. 2007; Pikitch et al. 2004), as ecosystem resilience and fishery productivities depend on food web process and structures that can be changed by fisheries and other human activities (Andersen et al. 2015; Francis et al. 2007; Marasco et al. 2007). Therefore, food web interactions should be considered in the modeling for EBFM and EBM (Francis et al. 2007; Marasco et al. 2007).

The models that incorporate the food web process (predator-prey relations or interspecific competition) and economic components, called the multispecies bio-economic model in the later part of this paper, can be traced back to Clark (1976, 2010), Hannesson (1983), Conrad and Adu-Asamoah (1986) in which the biological part of the models used lumped biomass for each species. Since then, numerous numerical applications of multispecies bioeconomic models with age-structured have been developed and applied for different marine ecosystems worldwide (see the review in Nielsen et al. (2018)). For the Baltic Sea regions, the age-structured multispecies bio-economic models were mainly developed for the food web relations among cod (Gadus morhua), sprat (Sprattus sprattus), and herring (Clupea harengus) (Bastardie et al. 2012; Hutniczak 2015; Nieminen et al. 2012; Voss et al. 2014a, b; Yun et al. 2017). ICES (2013a) has also begun to give advice based on the multispecies assessment of cod, sprat, and herring for the Baltic Sea. Mammal predators (e.g., grey seals 
(Halichoerus grypus)) were included in some multispecies bio-economic models but solely in the biological part of the models (Blenckner et al. 2011; Bossier et al. 2018). In addition, the important migratory fish, salmon (Salmo salar), in the Baltic Sea have not been involved in those multispecies bio-economic models or multispecies management advice.

Salmon is an important commercial fish in the Baltic Sea, and its recreational catch has continued to rise in recent years (ICES 2013a, 2016). From the ecological perspective, salmon occupies an irreplaceable niche in the river ecosystem, providing supporting services such as maintaining the food web balance in rivers, transporting nutrients, reducing sedimentation, and so on (Kulmala et al. 2013). Although the importance of Baltic salmon seems more obvious in the river ecosystems, the population dynamics of salmon are strongly affected by predators, prey, and diet during the migration at sea (e.g., Ikonen (2006); Mäntyniemi et al. (2012); Mikkonen et al. (2011); Rudstam et al. (1994); Suuronen and Lehtonen (2012)). The food web relations between salmon and other species and types of salmon fisheries are closely associated with the migration routes and life stages of salmon. The post-smolt stage of salmon covers the period from spring, when young salmon (smolts) arrive the sea, to the end of their first winter at sea. For the salmon populations born in the rivers that flow into the Gulf of Bothnia, the northernmost Baltic Sea, post-smolts migrate southward through the Gulf to reach the Baltic main basin by the end of the post-smolt stage (Ikonen 2006). During this stage, salmon mortality is affected by the abundance of grey seal (predators) and young herring (prey) in the Gulf of Bothnia (Kallio-Nyberg et al. 2011; Mäntyniemi et al. 2012; Salminen 2001). These salmon populations remain at sea for 1-4 years for feeding and then migrate northward, mostly along the east side of the Northern Baltic Sea, to their home rivers for spawning when they are mature (Ikonen 2006). The grey seal is also a threat to salmon during this spawning migration (Suuronen and Lehtonen 2012).

Herring in the Gulf of Bothnia are also a food source for grey seals (Gardmark et al. 2012; Lindegren et al. 2011; Lundström et al. 2010). The grey seal-herring and salmonherring relations are only explored in ecological studies (Gardmark et al. 2012; Lindegren et al. 2011; Lundström et al. 2010; Mäntyniemi et al. 2012; Salminen 2001) but are not yet developed in the bio-economic model. The well-developed bio-economic models for Baltic salmon are mainly single species approaches (e.g., Kulmala et al. (2008); Laukkanen (2001)). Moreover, the effects of grey seal on salmon are only included as impacts on salmon fishery harvests (Holma et al. 2014; ICES 2016) or are embedded within all sources of natural mortality in the salmon stock assessment (ICES 2014; Michielsens et al. 2006); they are not included as a direct prey-predation interaction between grey seal and salmon populations.

Therefore, this study develops a multispecies bio-economic model with three trophic levels involving the food web interactions of grey seals, salmon and herring in the Northern Baltic Sea. The study has two aims. The first aim is to explore how the economically optimal harvest of the Northern Baltic salmon fisheries and the development of the corresponding salmon stock are influenced by the prey and predators of salmon. For this purpose, we apply this multispecies model in a single species management context and maximize the profit of the salmon fisheries in different levels of seal populations and herring fishing mortality. This allows us not only to evaluate the consequences of the multispecies interactions but also to compare the results between our multispecies model and single species salmon model. The second aim is to explore the trade-off between salmon and herring fisheries under a multispecies management context with different management policies. This reveals answers to the question on which management policy is economically preferred. For this purpose, we designed different scenarios, including that herring and salmon 
fisheries manage the harvest at the levels that can maximize the total profits from both fisheries and that the two fisheries apply different management approaches (e.g., maximizing the long-term profits or harvest of the individual fishery) simultaneously.

\subsection{Study Scope}

As mentioned, the ecological part of the study scope covers grey seals, salmon and herring in the Northern Baltic Sea. In addition, the economic part includes salmon fisheries along the Finnish coast and herring fisheries in the Gulf of Bothnia.

We focus on the salmon population from Tornionjoki (River Torne), the northernmost spawning areas for Baltic salmon. Tornionjoki is the most productive river for the salmon smolts, accounting for almost half of the total wild smolt production in the Baltic region (ICES 2015b). Due to the closures of drift netting throughout the Baltic Sea and fishing challenges for offshore salmon fisheries in the Gulf of Bothnia, Baltic salmon are mainly harvested by (1) offshore longline fishing on feeding salmon at the Baltic main basin; (2) coastal trap net fishing of salmon during their spawning migration; and (3) recreational fishing for salmon entering rivers for spawning (ICES 2015b). During their spawning migration, Finnish coastal trap nets are the largest contributor to the commercial catch of the Tornionjoki population (ICES 2015b).

Herring from the Gulf of Bothnia are only caught by Finland and Sweden. The herring stock is currently higher than the sustainable level under the maximum sustainable yield (MSY) policy. However, the catch is in an increasing trend and fishing pressure was above the MSY level in 2016 (ICES 2017a). Herring fisheries at the Gulf of Bothnia are especially important for Finland. In 2016, the Finnish herring harvest from the Gulf of Bothnia accounted for $68 \%$ of the total fish harvest in Finland, measured by weight (LUKE 2016).

Due to the salmon migration route and the target herring population, we only considered the grey seal population in the Northern Baltic Sea, which includes data for the Gulf of Bothnia, Central Sweden, and the Southwestern Finnish Archipelago, based on counting information from HELCOM SEAL Expert Group (2015). The mobility of grey seals is high (Harding et al. 2007). Therefore, although the population of grey seal in the Baltic Sea continues to grow, their abundance fluctuates within each subarea (HELCOM SEAL Expert Group 2015).

In the next section, which addresses our methodology, we introduce our model in the order of model scheme and then the detail of the biological and economic components of the model. Section 3 describes the scenario design of this study. Section 4 shows the results. The final section presents the discussion and concludes the key insights of this study.

\section{Methodology}

\subsection{Model Scheme}

The submodels of each species are age-structured models because such models can show the assumed links between the different life stages of a species and other species, which are suitable for multispecies models (deYoung et al. 2004). Figure 1 explains the relationship among the submodels. Herring and grey seals affect the mortality rate of salmon at the salmon stages of post-smolt and spawning migration; grey seals also influence the 


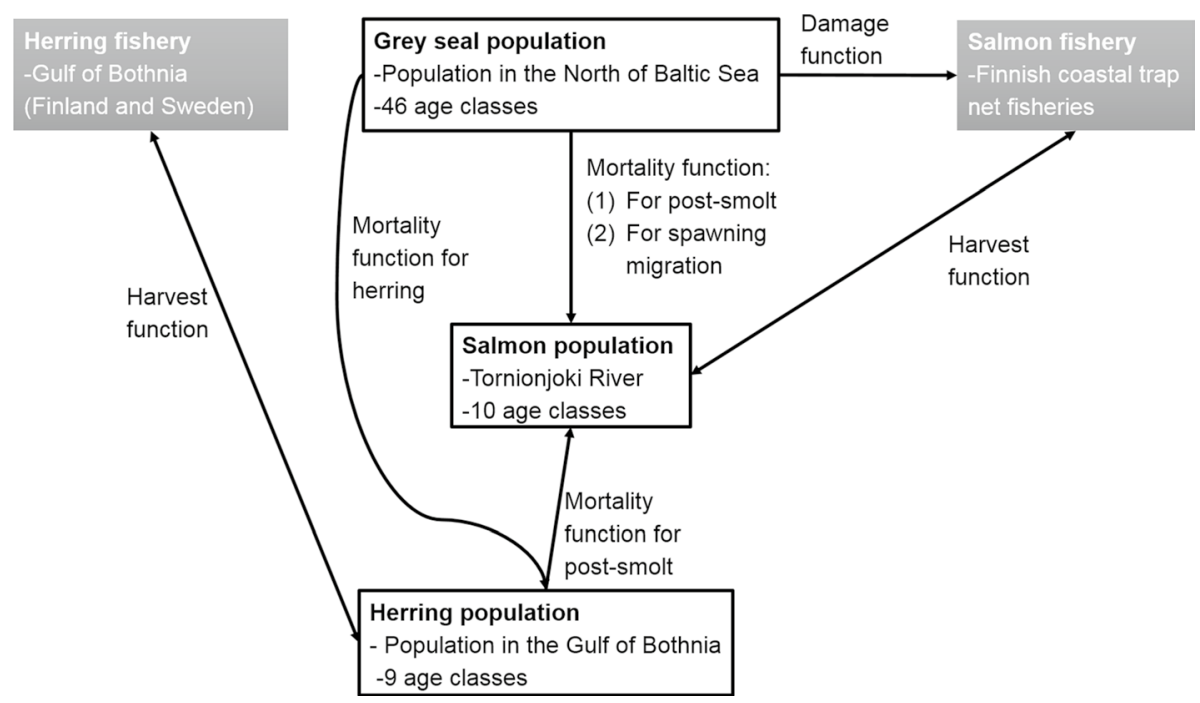

Fig. 1 Model scheme (revised from Holma et al. (2014)): the white boxes show the biological submodels, and the grey boxes show the economic submodels. The positions of the boxes represent their locations at the trophic level. The arrows show the effect directions among the submodels

mortality of herring. As capturing all relationships in the system will make the model intractable due to the complexity and is not possible due to the lack of data, simplifying the model is necessary (deYoung et al. 2004). One simplification is that the seal population is determined by different settings of carrying capacity but the carrying capacity is not involved in the optimization in all the modelling scenarios. In addition, our model does not include feedback effects among the species, which is shown as the one-way direction of the arrows among the submodels in Fig. 1. The reason is that the biomass of salmon at sea is almost negligible compared to other species in the Baltic Sea. Based on the estimated salmon numbers (0.5-2.3 million individuals) in the marine feeding ground and the average weight of salmon (ICES 2015b), the total stock biomass (TSB) of herring in the Gulf of Bothnia (ICES 2017b) was more than 40 times larger than the estimated biomass of salmon at sea. In addition, the frequency of salmon eaten by grey seals is relatively low compared to other prey (Lundström et al. 2010; Stenman 2007; Suuronen and Lehtonen 2012). ICES (2017b) also indicated that salmon has fewer influences than other predators (e.g., seals and cormorants) on herring in the Gulf of Bothnia. Therefore, we assumed that salmon as prey or predators have little influence on other species. We also assumed that grey seals are not influenced by the prey species, as grey seals have opportunistic eating habits and a switchable diet (Marasco et al. 2007; Ministry of Agriculture and Forestry 2007). Grey seals have various food sources (e.g., vendace, herring, sprat, salmon, and whitefish), and the biomass share of different prey in grey seals' digestive tract varied in the studies (Lundström et al. 2010; Suuronen and Lehtonen 2012).

There are two-way arrows between the fish population and fisheries (Fig. 1), showing that the harvest activities from fisheries affect the population level, but the harvest amount also depends on the population level. Grey seals eat mature salmon from both salmon trap nets and the open sea (Lundström et al. 2010; Suuronen and Lehtonen 2012). This implies that grey seals contribute both a natural mortality rate to the salmon population through mortality function and a fishery cost through the damage function at this spawning 
Table 1 Population models for each species

\begin{tabular}{llll}
\hline Species Equations & Herring $(h)$ & Grey seal $(g)$ & Salmon $(s)$ \\
\hline Types of stock-recruit function & Ricker & Beverton-Holt & Beverton-Holt \\
$(1) N_{a, t+1}^{\text {species }}=S U R_{a-1, t}^{\text {species }} \cdot N_{a-1, t}^{\text {species }}$ & $a=2$ to 9 & $a=2$ to 46 & $a=2$ to 10 \\
$(2) N_{1, t+1}^{\text {species }}=$ & $S S B_{t}^{h} \cdot\left(c \cdot e^{-d \cdot S S B_{t}^{h}}+\frac{\sigma}{2}\right)$ & $\sum_{a=1}^{46} F E C_{a}^{g} \cdot N_{a, t}^{g}$ & $\sum_{a=1}^{10} F E C_{a, t}^{s} \cdot N_{a, t}^{s}$ \\
\hline
\end{tabular}

migration stage (Holma et al. 2014; ICES 2016; Michielsens et al. 2006). The damage function refers to the impact that salmon are eaten by seals from the fishery catch (in trap nets), which was adopted from Holma et al. (2014).

\subsection{Biological Model}

Equations (1) and (2) (in Table 1) describe the population structure of the submodels for each species. The grey seal model and the salmon model were extended from Holma et al. (2014), and the herring model was revised from ICES (2013b), Nieminen et al. (2012) and Kulmala et al. (2007). Depending on which species is referenced, the superscript species in the Eq. (1) and (2) are replaced by $g$ (grey seal), $s$ (salmon), or $h$ (herring). $N_{a, t+1}^{\text {species }}$ is the number of individuals at age class $a$ in the year $t+1$, which equals the individual from age class $a-1$ in the year $t$ multiplying the survival rate $\left(S U R_{a-1, t}^{\text {species }}\right)$ for age class $a-1$ in the year $t$. Equation (2) represents the individual numbers of age class 1 at year $t+1$. The number of herring in age class 1 is determined by the spawning stock biomass (SSB) of herring and the Ricker stock-recruitment function (ICES 2013b; Nieminen et al. 2012). The Beverton-Holt stock-recruitment function was used for grey seal (Holma et al. 2014) and salmon (Michielsens et al. 2008) submodels. The newly hatched individuals equal the sum of the product from fecundity per capita $(F E C)$ and the number of individuals at each age class from the previous year. The restriction of population density is in the survival rate $(S U R)$ at age class 1 (for grey seal) and age class 4 (for salmon). "Appendix 1" explains the details of each population model and the parameter values ${ }^{1}$. In the remainder this section, we focus on the connecting mechanisms among the submodels of different species shown in Fig. 1.

\subsubsection{Mortality Function of Homing Salmon}

The first connection mechanism among the species model is the mortality rate of homing salmon, which is embedded in the salmon fecundity per capita $\left(F E C_{a, t}^{s}\right)$ in Eq. (2). The components of the fecundity per capita are written as follows:

$$
F E C_{a, t}^{s}=F e_{a}^{s} \cdot s r_{a}^{s} \cdot h r_{a} \cdot\left(e^{-q_{a}^{s} \cdot E_{t}^{s}-m o \cdot M N^{s}+L n\left(1-M G_{t}^{s}\right)}\right)
$$

In Eq. (3), fecundity $\left(F e_{a}^{s}\right)$, sex ratio $\left(s r_{a}^{s}\right)$, homing rate $\left(h r_{a}\right)$, and survival from fishing $\left(e^{-q_{a}^{s} \cdot E_{t}^{s}}\right)$ are the same as in Holma et al. (2014). The original function from Holma et al. (2014) implies that homing salmon only die due to fishing. The natural instantaneous mortality rate, $m o \cdot M N^{s}$, was added into the function based on Kulmala et al. (2008) and Michielsens et al. (2006), as natural mortality also occurs during the spawning migration. The value of mo equals $\frac{5}{12}$, which means that the migration period is 5 months every year (Kulmala et al. 2008). An additional seal-related mortality was suggested to increase the instantaneous natural mortality rate due to the increased grey seal population (Michielsens 
et al. 2006). Therefore, this study added a new component, $\operatorname{Ln}\left(1-M G_{t}^{S}\right)$, into total instantaneous mortality rate based on Ricker (1975). The $\operatorname{Ln}\left(1-M G_{t}^{s}\right)$ is the negative instantaneous mortality rate from grey seal predation since $M G_{t}^{s}$ is the finite mortality rate from grey seal predation on homing salmon:

$$
M G_{t}^{s}=\frac{N m a_{t}^{g} \cdot N o r B o \cdot s g}{\sum_{a=1}^{10} h r_{a} \cdot N_{a, t}^{s}}
$$

In Eq. (4), the numerator represents the number of salmon eaten by grey seal during the homing period, and the denominator represents the total number of homing salmon. The numerator consists of the number of grey seals $\left(\mathrm{Nma}_{t}^{g} \cdot \mathrm{NorBo}\right)$ and the number of salmon eaten per seal $(s g)$ during the migration period. The total adult seal population in the study area $\left(N m a_{t}^{g}\right)$ is defined in "Appendix 1". Only adult seals were considered, since salmon were discovered to be more common in adult and larger seals' diets (Lundström et al. 2010; Suuronen and Lehtonen 2012). NorBo is the proportion parameter to calculate the grey seal population in the Gulf of Bothnia.

The value of $s g$ is 5 and was estimated based on the following procedures. First, based on Gardmark et al. (2012), the weight of salmon eaten per seal per day was determined by $\frac{8.1 \% \times 24.7\left(\mathrm{MJ} \mathrm{d}^{-1}\right)}{4.33\left(\mathrm{MJ} \mathrm{kg}^{-1}\right)}=0.46\left(\mathrm{Kg} \mathrm{d}^{-1}\right)$, where $8.1 \%$ is the proportion of the salmon biomass in the grey seals' diet from Lundström et al. (2010), $24.7 \mathrm{MJ} \mathrm{d}^{-1}$ is average daily metabolic rate of seal from Gardmark et al. (2012), and $4.33 \mathrm{MJ} \mathrm{kg}^{-1}$ is the average energy content of homing salmon considering both females and males (Jonsson and Jonsson 2003). Further, the number of salmon eaten per seal during the migration period was estimated as $\frac{0.46\left(\mathrm{Kg} \mathrm{d}^{-1}\right) \times 60(\mathrm{~d})}{5.5\left(\mathrm{~kg} \mathrm{fish}^{-1}\right)}=5$ (fish). We followed ICES (2014) and used only 60 days to consider seal predation, as salmon were only discovered in seal stomachs in June and July (Suuronen and Lehtonen 2012); $5.5\left(\mathrm{~kg} \mathrm{fish}^{-1}\right)$ is the average weight of homing salmon estimated by the initial salmon population, homing rate, and weight by ages listed in Table 10 .

\subsubsection{Mortality Function of Post-Smolt}

The second connection mechanism among the submodels is the salmon survival rate at the post-smolts stage. In our age-structured model, the survival rate of the post-smolt stage is

$$
S U R_{5, t}^{s}=\mathrm{e}^{-M p s_{t}^{s}},
$$

where $M p s_{t}^{s}$ is the instantaneous mortality rate of post-smolts. $M p s_{t}^{s}$ was estimated by following the Bayesian approach from Mäntyniemi et al. (2012) with updated data to 2014 from ICES (2016) and ICES (2017b):

$$
M p s_{t}^{s}=\delta \cdot N_{t}^{g}+e^{\left(\varphi-\rho \cdot \frac{S S B_{t}^{h}}{N_{5, t}}\right)},
$$

where $e^{(\varphi)}$ is the instantaneous mortality rate without grey seal and herring; $e^{\left(-\rho \cdot \frac{S B_{t}^{h}}{N_{5, t}^{s}}\right)}$ represents that food availability and herring SSB per post-smolt $\left(\frac{S S B_{t}^{h}}{N_{5, t}^{s}}\right)$ will lower the mortality; and $\delta \cdot N_{t}^{g}$ means that the grey seal population will increase the mortality rate. Notice that we used herring SSB to replace 0+herring (actual food sources for post-smolts (Mäntyniemi et al. 2012)) because the youngest herring data start from age 1 . We took the median value from Bayesian results for the parameters: $\delta=0.0000345, \varphi=0.2238$, and 
$\rho=0.08129$. The data used for estimation and the fitness check of the model can be seen in "Appendix 1" and "Appendix 3", respectively.

\subsubsection{Mortality of Herring from Grey Seal}

To include the impact of grey seals on the herring population, we estimated the weight of herring eaten by grey seals each year using the following process. First, we used the length distribution in digestive tract content from grey seals (Gardmark et al. 2012) and the data on length at age (MAF and FGFRI 2014) to estimate the age distribution of herring eaten by grey seals. Second, we used the data from Gardmark et al. (2012) to estimate the weight of herring consumed by one seal per year. Then, using the results from the first two steps together with the data of weight at age (MAF and FGFRI 2014), we can estimate the number of herring eaten per grey seal by age class. We included this "numbers of herring eaten per grey seal by age class" in the herring population model in estimating SSB and the number of individuals (see Eqs. 25, 26, 28 and 29 in "Appendix 1").

\subsubsection{Carrying Capacity of the Grey Seal Population}

The relations described between Sect. 2.2.1 and Sect. 2.2.3 are influenced by grey seal population dynamics. Therefore, different levels of carrying capacity are used to decide the grey seal population in different scenarios (see Sect. 3). Although the carrying capacity of grey seals in the Baltic Sea was more than 90,000 individuals based on the historical record (Harding et al. 2007), the mortality relations from Sect. 2.2.1 to 2.2.3 were built based on seal population data before 2014 , which were at lower levels. The model is sensitive to the size of the seal population, and thereby indirectly the carrying capacity of seals. If the seal population is too high, the mortality relations described in Sect. 2.2.1-2.2.3 will not be valid and will cause negative populations for herring and salmon. Thus, we determined the carrying capacity of the entire Baltic Sea in our model as 37,000 and 50,000 individuals in different scenarios (see Sect. 3). We argue that such settings of carrying capacity are not an issue as the grey seal population has been relatively stable after 2014, though it has a slight increase in 2019 (Anders et al. 2020). Setting the carrying capacity as 37,000 individuals represents the assumption that the seal population has reached its maximum and, if nothing changes, remains at recent levels in the future as it is close to the counted seal numbers in 2014 (32,019 individuals reported by HELCOM SEAL Expert Group (2015)) multiplied by the hidden parameter 1.15 (Holma et al. 2014). This hidden parameter is used to include the unobserved seals to total seal population as the reported seal number from HELCOM SEAL Expert Group (2015)) was observing data. In contrast, setting carrying capacity as 50,000 individuals implies the assumption that the grey seal population may continue to increase.

\subsection{Economic Model}

This section describes the profit functions of salmon and herring fisheries and the harvest functions in Fig. 1. 


\subsubsection{Profit Function for Salmon Fisheries}

The profit of salmon fisheries $\left(\pi_{t}^{s}\right)$ in year $t$ is written as Eq. (7), which is the difference between revenue $\left(R_{t}^{s}\right)$ and $\operatorname{cost}\left(C O_{t}^{s}\right)$ from fishing.

$$
\begin{gathered}
\pi_{t}^{s}=R_{t}^{s}-C O_{t}^{s}=P_{a}^{s} \cdot\left(H_{a, t}^{s}-D G_{a, t}^{s}\right)-\left(y \cdot c o_{1}^{s}+(1-y) \cdot c o_{2}^{s}\right) \cdot E_{t}^{s} \\
D G_{a, t}^{s}=w \cdot H_{a, t}^{s} \cdot\left(y \cdot Z_{t}^{s 1}+(1-y) \cdot Z_{t}^{s 2}\right)
\end{gathered}
$$

The revenue part consists of the price and numbers of harvest. The prices of salmon $\left(P_{a}^{s}\right)$ are constant, since the fisheries are assumed to be part of a world market, but the prices differ in age classes due to the size variance of salmon. The valuable harvest numbers exclude the damage from seals by age $\left(D G_{a, t}^{s}\right.$, Eq. (8), based on Holma et al. (2014)), from the total harvest by age $\left(H_{a, t}^{s}\right)$. The harvest function showed in Fig. 1 is $H_{a, t}^{s}=\left(1-e^{-q_{a}^{s} \cdot E_{t}^{s}}\right) \cdot h r_{a} \cdot N_{a, t}^{s}$, from Holma et al. (2014). In addition, $Z_{t}^{s 1}$ and $Z_{t}^{s 2}$ are the damage function (Fig. 1) to estimate the salmon that are caught in the fishing gears but damaged by seals. $Z_{t}^{s 1}$ and $Z_{t}^{s 2}$ are for seal-safe gears ${ }^{2}$ and traditional gears, respectively. The hidden loss, $w$, in Eq. (8) is given as 1.2 (Fjälling 2005; Holma et al. 2014), which is used to calibrate total damaged salmon from seals as $Z_{t}^{s 1}$ and $Z_{t}^{s 2}$. Such calibration is needed as the damage functions are estimated based on the observable damaged salmon from seals (Fjälling 2005; Holma et al. 2014). In Eq. (8), the proportion of seal-safe gears ( $y$ ) and traditional gears (1-y) is given as 0.65 and 0.35 , respectively. This given proportion is to achieve the amount of seal damage that accounted for $8 \%$ of the total harvest in the initial year of the modeling to match the seal damage rate in Finnish trap net fisheries in 2014 (ICES 2015b). The same share of seal-safe and traditional gears is also applied for the cost elements in Eq. (7), where $c o_{1}^{s}$ is the unit cost per gear day for seal-safe gears and $c o_{2}^{s}$ is traditional gears. The total cost equals the weighted average unit cost multiplied by the gear days $\left(E_{t}^{s}\right)$. The value of the price, cost, components of damage function, harvest function, and the relevant references of the values and functions can be found in "Appendix 1".

\subsubsection{Profit function for Herring Fisheries}

Similar to salmon fisheries, profit for herring fisheries is also total revenue minus total cost:

$$
\pi_{t}^{h}=R_{t}^{h}-C O_{t}^{h}=X_{t} \cdot H_{t}^{h} \cdot P_{\text {fodder }}^{h}+\left(1-X_{t}\right) \cdot H_{t}^{h} \cdot P_{\text {food }}^{h}-c o^{h} \cdot \frac{F_{t}^{h}}{q^{h}}
$$

The prices for herring vary depending on the using purpose of herring, i.e. herring used for human consumption or for fodder, rather than age or size of herring. Accordingly, the total harvest in Eq. (9) is not the number of individuals but their biomass: $H_{t}^{h}=\sum_{a=1}^{9} A W_{a}^{h} \cdot H_{a, t}^{h}$, where $A W_{a}^{h}$ is average weight by age. The harvested individual by age $\left(H_{a, t}^{h}\right)$ was estimated by the harvest function from Kulmala et al. (2007), Nieminen et al. (2012) and ICES (2013b):

$$
H_{a, t}^{h}=\left(\frac{o_{a}^{h} \cdot F_{t}^{h}}{M N^{h}+o_{a}^{h} \cdot F_{t}^{h}}\right) \cdot N_{a, t}^{h} \cdot\left(1-e^{\left(-M N^{h}-o_{a}^{h} \cdot F_{t}^{h}\right)}\right),
$$


where $\left(\frac{o_{a}^{h} \cdot F_{t}^{h}}{M N^{h}+o_{a}^{h} \cdot F_{t}^{h}}\right)$ is the proportion of fishing mortality over total mortality and $\left(1-e^{\left(-M N^{h}-o_{a}^{h} \cdot F_{t}^{h}\right)}\right)$ is the total mortality rate. "Appendix 1" provides the detail meaning and values of the components in these mortalities. Because the herring market prices are different for fodder and human consumption in Finland (Kulmala et al. 2007; Nieminen et al. 2012), Nieminen et al. (2012) introduced proportion $X_{t}$, which considers young herring from age classes 1 to 4 as fodder. ICES (2015a) indicated that the Swedish herring catch in the Gulf of Bothnia is mainly for human consumption and that the Swedish Bothnian herring catch accounted for $10 \%$ in 2013 . Therefore, $X_{t}$ in our model was determined as $\frac{0.9 \cdot \sum_{a=1}^{4} H_{a, t}^{h}}{H_{t}^{h}}$, and $\left(1-X_{t}\right)$ is the proportion of herring for human consumption.

In the cost part, $c o^{h}$ is the average unit cost per gear day. The value of $c o^{h}$ is $4,868 €$ $(=0.976 \times 4.988 €)$ in the model, where 0.976 is to exclude the sprat catch share in the Gulf of Bothnia (ICES 2015a). The cost of 4,988 € was estimated based on the fleet cost data of Finland and Sweden from the economic report on the EU fishing fleet (European Commission 2015). This cost estimation was based on: (1) the catch share between Finland (90\%) and Sweden (10\%), and (2) the catch share in gear types. For the catch share in gear types, pelagic trawls plus demersal trawls caught $95 \%$ of herring from Gulf of Bothnia in 2013 (ICES 2015a), and other gears accounted for the rest (5\%) of the catch. The fishing gear days of herring were determined as $\frac{F_{t}^{h}}{q^{h}}$ (Nieminen et al. 2012), where $q^{h}$ is catchability. The value of catchability was estimated by the catch amount, gear days and TSB from ICES (2017b).

\section{Scenarios and Optimization}

\subsection{Scenarios for Single Species Management Context}

As mentioned in the introduction, we start out by designing scenarios where the management of the salmon fishery is in a single species management context while the biological part is in a multispecies model. This is to explore the consequences of changing fishing efforts in herring fisheries and seal population on the economically optimal harvest of salmon fisheries and the salmon population. We assume that salmon fisheries adopt a maximum economic yield (MEY) policy, which refers to manage their harvest at the level that can maximize the net present value (NPV) of their long-term profit in this paper. The optimization problem for the scenarios is defined as the following objective (Eq. (11)) and constraint (Eq. (12)) functions:

$$
\begin{gathered}
\max _{E_{t}^{s}} \sum_{t=1}^{T} \pi_{t}^{s}\left(H_{t}^{s}\left(E_{t}^{s}, D G_{t}^{s}\left(N_{t}^{g}\right)\right), P^{s}, C O_{t}^{s}\left(E_{t}^{s}\right)\right) \cdot\left(\frac{1}{1+r}\right)^{t-1} \\
\text { s.t. } N_{a, t}^{s}\left(N_{t}^{g}, S S B_{t}^{h}\left(F_{t}^{h}, N_{t}^{g}\right), H_{a, t}^{s}\left(E_{t}^{s}, D G_{a, t}^{s}\left(N_{t}^{g}\right)\right)\right) \geq 0
\end{gathered}
$$

The objective function maximizes the NPV of salmon fisheries' profit $\left(\pi_{t}^{s}\right)$ by optimizing the fishing effort $\left(E_{t}^{s}\right)$ for $T$ years. To make the steady state clear enough, the simulation periods for the food web interaction scenarios are 150 years $(T=150)$. In Eq. $(11),\left(\frac{1}{1+r}\right)^{t-1}$ is the discount factor, where $r$ is the discount rate. The constraint function is the dynamics of the 
Table 2 Summary of the scenarios in the single species management context to explore the effective of change in herring fishing mortality and seal population on optimization of salmon fisheries

\begin{tabular}{llll}
\hline Scenario code & Salmon fisheries & Herring fishery & Seal population \\
\hline Baseline & Management by MEY policy & $F_{t}^{h}=0.20$ (2014 level) & $K=37,000$ (2014 level) \\
I-S & & $F_{t}^{h}=0.20$ & $K=50,000$ (Increase) \\
I-H & $F_{t}^{h}=0.25$ (Increase) & $K=37,000$ \\
I-HS & $F_{t}^{h}=0.25$ & $K=50,000$ \\
\hline
\end{tabular}

salmon population affected by the salmon harvest and the population dynamics of grey seals and herring. In the baseline scenario, we assumed that the levels of herring fishing mortality and grey seal abundance are constant and approximate to the 2014 level during the future simulation periods. In this case, the instantaneous fishing mortality rate of herring in Eq. (12) was determined as $0.2\left(F_{t}^{h}=0.20\right)$ (see 2014 value in ICES (2017a)), and the carrying capacity of the grey seal population $(K)$ is 37,000 (see Table 7 and Sect. 2.2.4). To examine the effects of the levels of prey and predator change on salmon fisheries and population, we designed three scenarios with the assumption that (1) seal population increases in the future $(K=50,000)$ (scenario I-S); (2) herring fishing mortality increases to $F_{t}^{h}=0.25$ (scenario I-H); and (3) both of the previous two cases occur simultaneously (scenario I-HS). The reasons for these scenarios are the increasing trend of herring harvest and fishing mortality in the Gulf of Bothnia (ICES 2017a) and the rising grey seal population in the Baltic Sea (Anders et al. 2020; HELCOM SEAL Expert Group 2015).

Table 2 summarizes the assumption of the scenarios and the short name of the scenarios. The solver, fmincon, in the MATLAB ${ }^{3}$ Optimization Toolbox was used to search the optimal solution in each scenario.

\subsection{Multispecies Management Approaches}

In addition to explore the results of single species management approach of salmon fisheries with different levels of predator and prey, our model could also simulate multispecies management since it includes the biological and economic interactions of different species. A common way to simulate the multispecies management is to optimize the aggregated or mean profit from different fisheries (e.g., Nieminen et al. (2012) and Voss et al. (2014b)) to find out social optimal as a whole. Thus, we simulated a multispecies management approach by maximizing the NPV of salmon and herring fisheries together as one objective function (scenario $\mathrm{S}_{\mathrm{MEY}}-\mathrm{H}_{\mathrm{MEY}}{ }^{1}$ ). The objective and constraint functions are defined as Eqs. (13-15), with the fishing effort of salmon fisheries $\left(E_{t}^{s}\right)$ and the fishing mortality of herring fisheries $\left(F_{t}^{h}\right)$ as control variables. $F_{t}^{h}$ was limited between 0 and 0.29 , which is also applied to other scenarios described later in this Sect. ${ }^{4}$.

$$
\begin{gathered}
\max _{E_{t}^{s}, F_{t}^{h}} \sum_{t=1}^{T}\left[\pi_{t}^{s}\left(H_{t}^{s}\left(E_{t}^{s}, D G_{t}^{s}\left(N_{t}^{g}\right)\right), P^{s}, C O_{t}^{s}\left(E_{t}^{s}\right)\right)+\pi_{t}^{h}\left(H_{t}^{h}\left(F_{t}^{h}\right), P^{h}, C O_{t}^{h}\left(F_{t}^{h}\right)\right)\right] \cdot\left(\frac{1}{1+r}\right)^{t-1} \\
\text { s.t. } N_{a, t}^{s}\left(N_{t}^{g}, S S B_{t}^{h}\left(F_{t}^{h}, N_{t}^{g}\right), H_{a, t}^{s}\left(E_{t}^{s}, D G_{a, t}^{s}\left(N_{t}^{g}\right)\right)\right) \geq 0
\end{gathered}
$$




$$
N_{a, t}^{h}\left(N_{t}^{g}, H_{a, t}^{h}\left(F_{t}^{h}\right)\right) \geq 0
$$

However, the trade-off among different species and fisheries is a crucial concern in multispecies management (Rindorf et al. 2013). The multiobjective concept and the Pareto frontier, which presents a set of optimal solutions in which no objective can be improved without making other objective worse off, have been used in several fisheries studies to show the trade-off among different objectives (Dujardin and Chades 2018; Enríquez-Andrade and Vaca-Rodríguez 2004; Vaca-Rodríguez and Enríquez-Andrade 2006). By applying the multiobjective optimization, we can analyze the trade-off between salmon and herring fisheries under different multispecies management contexts with designed scenarios. By comparing different multispecies management scenarios, including the scenario $\mathrm{S}_{\mathrm{MEY}}-\mathrm{H}_{\mathrm{MEY}}-1$ mentioned above, we can evaluate which multispecies management approach can achieve the highest benefit and the trade-off to achieve this benefit.

The scenarios for multiobjective optimization allow salmon and herring fisheries to have their own objective functions individually. For these scenarios, salmon fisheries can choose either MEY policy or the policy to maximize long-term harvest (called MH policy) as the management approach. Therefore, the objective function for salmon fisheries is Eqs. (11) or (16), depending on which policy to choose, with Eq. (12) as the constraint.

$$
\max _{E_{t}^{s}} \sum_{t=1}^{T} H_{t}^{s}\left(E_{t}^{s}, D G_{t}^{s}\left(N_{t}^{g}\right)\right)
$$

Simultaneously, herring fisheries can choose either MEY or MH policy. Objective and constraint functions for herring fisheries are Eqs. (17) and (18) when implementing MEY policy; changing the objective function from Eq. (17) to Eq. (19) is for herring fisheries to implement MH policy:

$$
\begin{gathered}
\max _{F_{t}^{h}} \sum_{t=1}^{T} \pi_{t}^{h}\left(H_{t}^{h}\left(F_{t}^{h}\right), P^{h}, C O_{t}^{h}\left(F_{t}^{h}\right)\right) \cdot\left(\frac{1}{1+r}\right)^{t-1} \\
\text { s.t. } N_{a, t}^{h}\left(N_{t}^{g}, H_{a, t}^{h}\left(F_{t}^{h}\right)\right) \geq 0 \\
\max _{F_{t}^{h}} \sum_{t=1}^{T} H_{t}^{h}\left(F_{t}^{h}\right)
\end{gathered}
$$

All the multispecies management scenarios are simulated with seal populations at 2014 levels $(K=37,000)$. The simulation period for multispecies management was determined as 50 years $(T=50)$. A longer period of simulation is not necessary, since the focus of these simulations is to explore the trade-off between the fisheries but not to find the steady state.

Table 3 summarizes the 5 designed scenarios. The MATLAB solver, fmincon, was used to search the optimal solution for single objective optimization (scenario

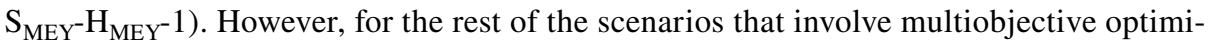
zation, we applied the solver, gamultiobj, in MATLAB Global Optimization Toolbox to find the Pareto frontier and the optimal solutions set (Paláncz et al. 2013). As the solver, gamultiobj, generates the results stochastically (Punnathanam et al. 2016), we simulated 10 times for each scenario and extract the points that represent the frontier most. 


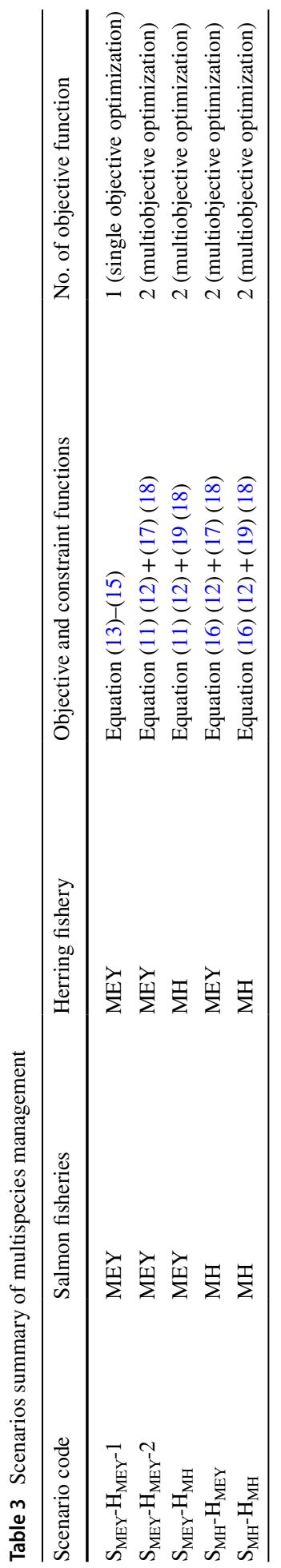




\section{Results}

\subsection{Comparison with Single-Species Model}

Our model is the first multispecies bio-economic model that includes salmon. Therefore, before analyzing how salmon fisheries and stocks are influenced by the population levels of predators and prey, we first compare the results between our multispecies model and the single species model from Holma et al. (2018), which used the model updated from Holma et al. (2014). We chose the I-H scenario (red dashed lines in Fig. 2), but not the Baseline scenario, as the comparison target. The reason is that the I-H scenario has steady states in which the herring and seal populations are close to their 2014 status (Fig. 3), which approaches assessment years in Holma et al. (2018). Figure $2 \mathrm{~b}$ and $\mathrm{c}$ show that the steady states of the salmon fishing effort and harvest in scenario I-H are not far from the results in Holma et al. (2018) (grey dotted lines in Fig. 2). In addition, the steady state of smolt production from this paper is 1.534 million for the I-H scenario, which is also close to Holma et al. (2018) results. The NPV is not comparable between the two studies, as the simulation periods are different. Our multispecies model takes a longer time to reach the steady states because of food web interactions. The results show that if the population of predators and prey approach the background assumption of the existing single species model, the multispecies model from this paper can produce similar results. Together with the results from retrospective simulation (Figs. 8, 9, 10 in "Appendix 2"), this multispecies model can demonstrate satisfactory simulation results.

\subsection{Influences of Predators and Prey}

In the scenarios of single species management context, both seal population growth (I-S scenario vs Baseline scenario) and low herring SSB due to the high fishing mortality (I-H scenario vs Baseline scenario) reduce the NPV, steady states of optimal harvest and fishing effort of salmon fisheries (Fig. 2b, c and Table 4), but seal population growth creates stronger effects. Although the impacts on salmon fisheries in the I-H scenario is smaller than that in the I-S scenario, the results from the I-H scenario reveal that a fishery can be indirectly affected by another fishery through food web relations.

When herring fishing effort and the seal population increase simultaneously (I-HS scenario), the harvest of salmon fisheries may drop to almost zero in some years (Fig. 2b). Compared to the Baseline scenario, the growing seal population (I-S or I-HS scenarios) can lead to more than $90 \%$ drop of salmon steady-state harvest and more than $30 \%$ drop of salmon fisheries' NPV (Table 4). However, the absolute value of this NPV loss from salmon fisheries is relatively small due to the small scale of the salmon fisheries. For example, in the I-S scenario, herring fisheries also lost $2.1 \%$ of NPV due to seal population growth, but the absolute value of this $2.1 \%$ NPV loss (8.2 million EUR) from the herring fisheries is significantly larger than the absolute value of the largest NPV drop (4.7 million EUR, 34.4\%) in the salmon fisheries.

The number of salmon spawners also decreases when the seal population grows and herring SSB decreases (Fig. 2a). However, the percentage reduction for salmon spawners is much smaller than that of the salmon harvest in the same scenario (Table 4). The reason is that the harvest of salmon trap net fisheries relies on salmon availability at sea (Holma et al. 2014). Declining herring SSB or increasing seal populations, which 
Fig. 2 Salmon spawners, harvest and fishing effort change attributable to the increased seal population and herring fishing effort
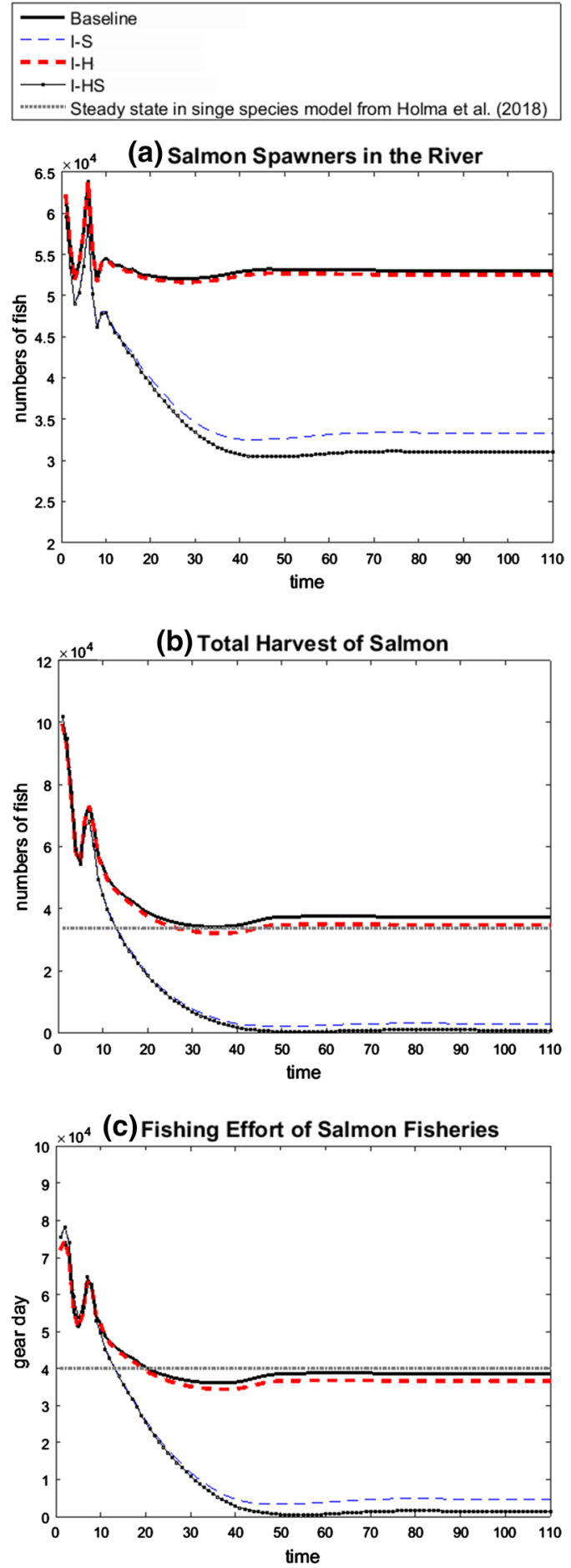


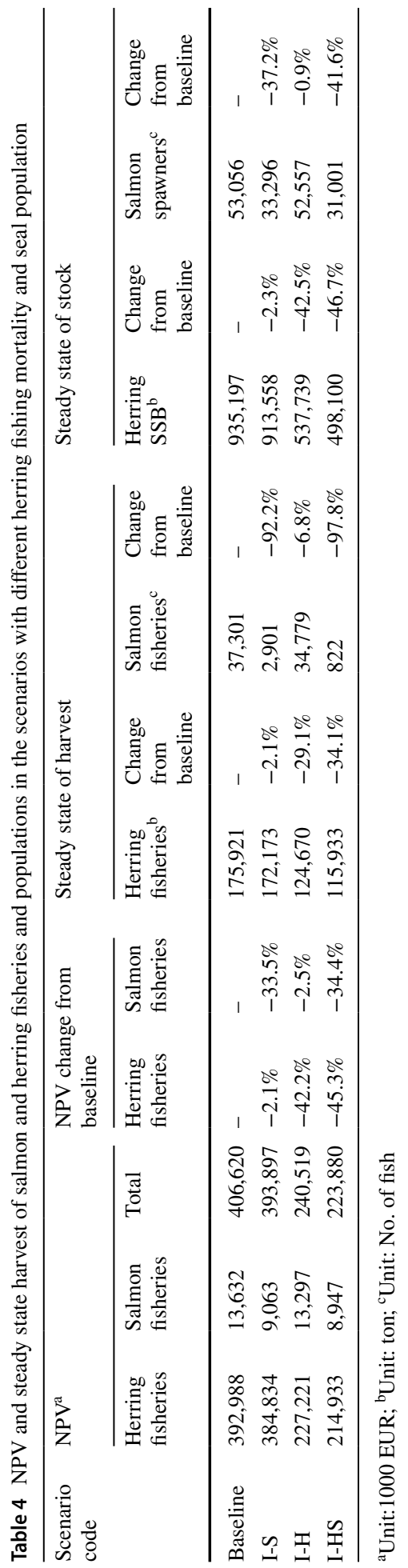



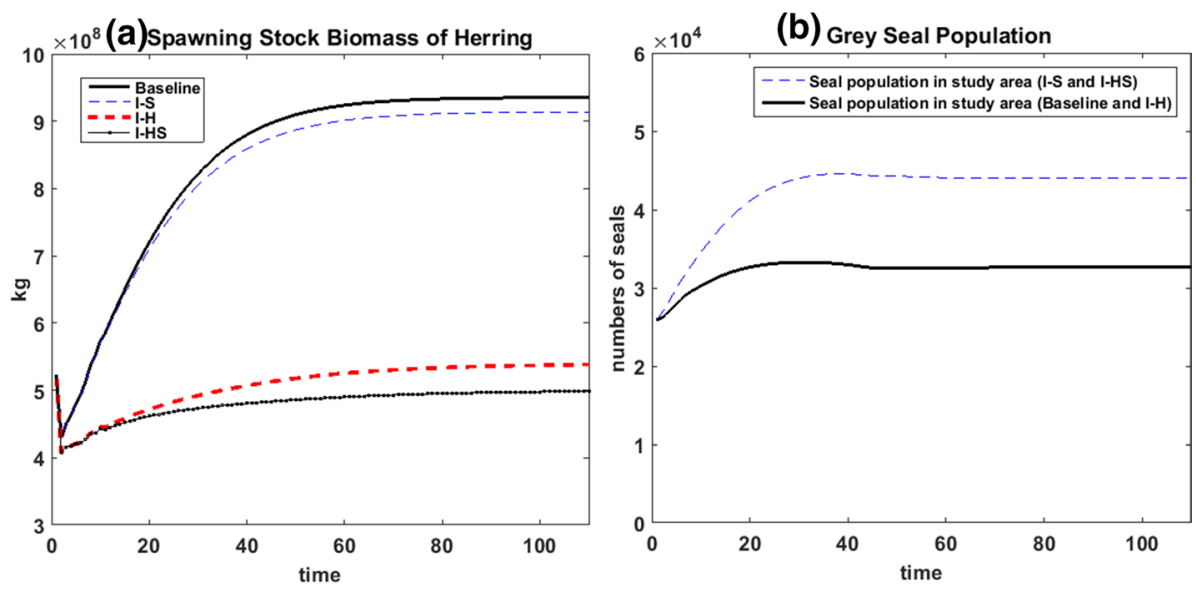

Fig. 3 Herring spawning stock biomass and seal population change

decrease the salmon population at sea, have negative impacts on the salmon harvest. Reducing the salmon harvest at sea, however, partly counteracts the negative biological effects of declining herring SSB and seal population growth on the salmon population. The results indicate that the performance of salmon fisheries may be influenced by the prey and predators of salmon and the potential indirect effects from herring fisheries, but salmon populations are relatively resilient regarding such food web effects if salmon are harvested according to the chosen policy.

As the model also include the food web relations between seals and herring, it is worth to analyze the results of herring fisheries and population as well. Although the herring SSB is slightly influenced by the rising seal population (Fig. 3b), the decreasing herring NPV and steady state of herring SSB (Table 4 and Fig. 3a) are mainly attributable to the increased herring fishing effort. Lower steady states on herring harvest with higher fishing mortality (Table 4, scenario I-H) result from the low steady states of herring SSB. In the Bassline and I-H scenarios in which seal populations are close to 2014 levels, herring eaten by grey seals per year range from 4300 to 5500 tons from the model simulation. This result corresponds to the estimation from ICES that herring eaten by grey seals has been approximately 5000 per year in the Bothnian Sea (Kuosa et al. 2017).

\subsection{Multispecies Management Approaches}

In this section, we compare the results of different multispecies management approaches, which vary in the chosen policies. Figure 4 shows the Pareto frontier (a set of optimal solutions) and the trade-off of the simulation results of different scenarios; Table 5 shows the NPV, total harvest, and average of fish stock from one of the optimal solutions (maximum summation of the profit or the median value) from Fig. 4 . When both fisheries take the

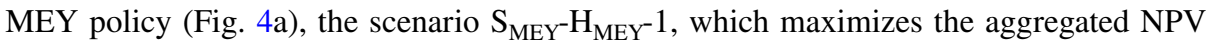
of both fisheries as one objective, has better performance than the two objectives approach

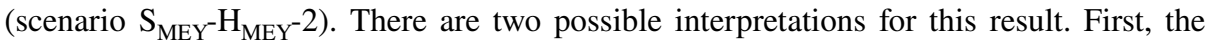
meaning behind the scenario $\mathrm{S}_{\mathrm{MEY}^{-}} \mathrm{H}_{\mathrm{MEY}}-2$ is that the profit from salmon is not replaceable by the profit from herring, and vice versa. Second, the optimization of herring fisheries 

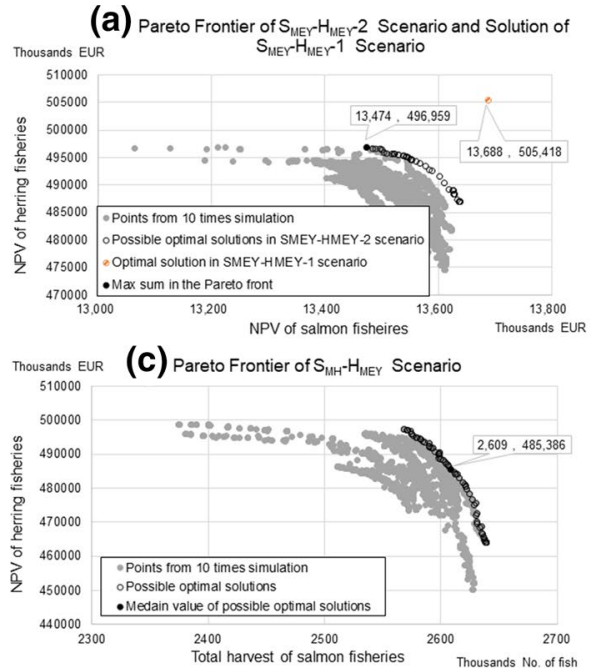

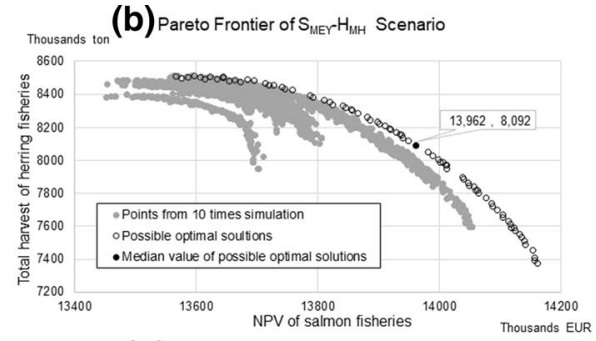

(d) Pareto Frontier of $S_{u H}-H_{u H}$ Scenario

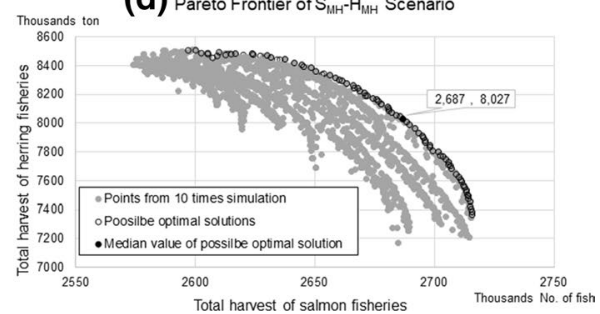

Fig. 4 Pareto frontier of the multispecies management scenarios

shows a cyclical behavior due to the model assumptions, e.g., non-perfectly selective fishing gears and the linear objective function (Tahvonen 2009; Tahvonen et al. 2012). The effects of this cyclical behavior from herring fisheries on the optimization of salmon fisheries can be better considered when maximizing the aggregated NPV of both fisheries.

Table 5 show that the conditions to make salmon and herring fisheries have good performance are different. For herring fisheries, scenario $\mathrm{S}_{\mathrm{MEY}}-\mathrm{H}_{\mathrm{MEY}}-1$ can reach the highest NPV and the highest total harvest among all the scenarios. Even the highest herring harvest in scenario $\mathrm{S}_{M E Y}-\mathrm{H}_{M H}$ (Fig. $4 b$ ) is lower than the harvest in scenario $\mathrm{S}_{M E Y}-\mathrm{H}_{M E Y}-1$. However, for salmon fisheries, scenario $\mathrm{S}_{\mathrm{MEY}} \mathrm{H}_{\mathrm{MH}}$ could reach higher salmon NPV in some of the possible solutions in which herring harvest is low enough. Comparing scenarios $\mathrm{S}_{\mathrm{MEY}}-\mathrm{H}_{\mathrm{MEY}}-1$ and $\mathrm{S}_{\mathrm{MEY}}-\mathrm{H}_{\mathrm{MH}}$ reveals that the highest aggregated NPV from the social perspective is achieved by high profit from herring fisheries but have a loss (or less profit) from salmon fisheries in exchange. If the policy target of salmon fisheries is to maximize the long-term harvest, both median value in scenario $\mathrm{S}_{\mathrm{MH}}-\mathrm{H}_{\mathrm{MEY}}$ and scenario $\mathrm{S}_{\mathrm{MH}}-\mathrm{H}_{\mathrm{MH}}$ in Table 5 can somehow reach the policy target, and scenario $\mathrm{S}_{\mathrm{MH}}-\mathrm{H}_{\mathrm{MH}}$ can achieve the highest salmon harvest (Fig. 4d).

In Table 5, the herring $\mathrm{SSB}$ in scenarios $\mathrm{S}_{\mathrm{MEY}}-\mathrm{H}_{\mathrm{MH}}$ (median value) and $\mathrm{S}_{\mathrm{MH}}-\mathrm{H}_{\mathrm{MH}}$ (median value) is higher than that in other scenarios resulting from the lower herring harvest to let salmon fisheries reach the targets of MEY or MH policy. For salmon stock, scenarios $\mathrm{S}_{\mathrm{MH}}-\mathrm{H}_{\mathrm{MEY}}$ (median value) and $\mathrm{S}_{\mathrm{MH}}-\mathrm{H}_{\mathrm{MH}}$ (median value) have lower salmon spawners than other scenarios due to the higher harvest level when pursuing the MH policy target. Table 5 seems to show that salmon fisheries are easier to reach the management target in scenarios $\mathrm{S}_{\mathrm{MEY}}-\mathrm{H}_{\mathrm{MH}}, \mathrm{S}_{\mathrm{MH}}-\mathrm{H}_{\mathrm{MEY}}$, and $\mathrm{S}_{\mathrm{MH}}-\mathrm{H}_{\mathrm{MH}}$. However, remember that Table 5 merely presents the results of one of the solutions in the optimal solutions set, and all solutions in the optimal set are equally good. Figure $4 \mathrm{~b}, \mathrm{c}$, and d reveal that herring fisheries could attain higher NPV or harvest closer to their management target in other options in the optimal solutions set. Our simulation results underline that a trade-off exists between herring and salmon fisheries. Together with the results from Sect. 4.2, this implies that the condition of herring fisheries may influence the performance of salmon fisheries. 


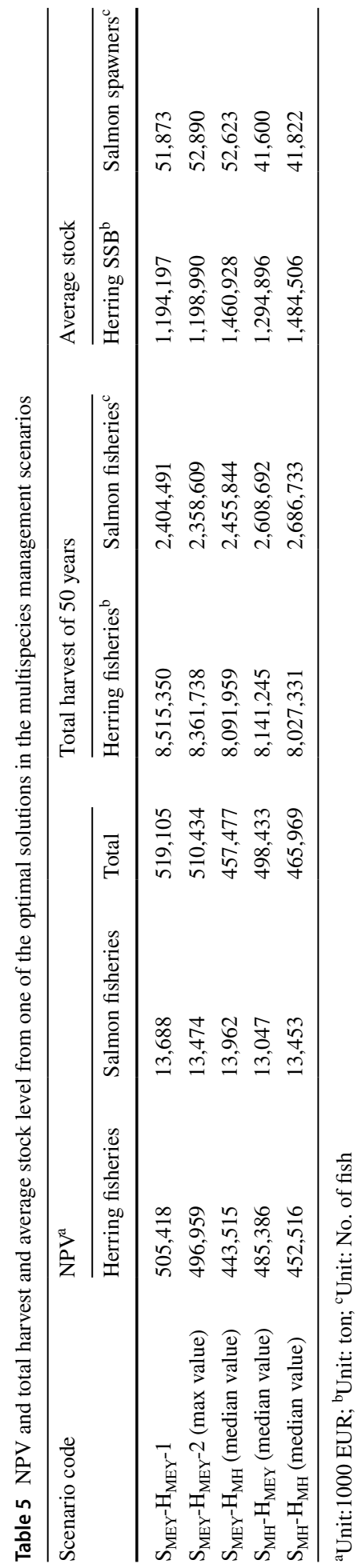




\subsection{Sensitivity Analysis}

To evaluate the sensitivity of some key biological and economic parameters, we conducted a sensitivity analysis for scenarios Baseline from Sect. 4.2 and $\mathrm{S}_{\mathrm{MEY}}-\mathrm{H}_{\mathrm{MEY}}-1$ from Sect. 4.3. Both the Baseline and the $\mathrm{S}_{\mathrm{MEY}}-\mathrm{H}_{\mathrm{MEY}}-1$ scenarios had the best economic performance within their scenario comparison, so we are interested in the sensitivity of such good performances. For both scenarios, the tested economic parameters include salmon price, cost, and interest rate. Scenario $\mathrm{S}_{\mathrm{MEY}}-\mathrm{H}_{\mathrm{MEY}}-1$ examined two more parameters, herring price and cost, which only influence herring NPV but not herring harvest and any other variables in the Baseline scenario. For the biological parameters, the key factors that build up the food web interactions: the three parameters of post-smolt mortality function and the parameter representing the number of salmon eaten by grey seals during the migration periods were tested for both scenarios. In addition, as the salmon recruitment condition seems to be a primary factor influencing the population dynamics of salmon (Kulmala et al. 2008) and it influences how the salmon population reacts to possible negative effects from other species, we also tested the salmon recruitment parameters. Considering the retrospective results in Fig. 10 ("Appendix 2"), herring recruitment parameters were also included. All the examined parameters increase $20 \%$ in the sensitivity analysis.

For scenario Baseline, changes in the economic and biological drivers of salmon do not influence herring population and fisheries in the sensitivity analysis. The changes of steady state of salmon spawners due to the parameter drivers are all within $\pm 15 \%$, which is relatively stable (Fig. 5a). Salmon price is the most crucial factor that influences salmon NPV. However, the salmon harvest is strongly influenced by one of the parameters for postsmolt mortality function, $\delta$, and the salmon recruitment parameters ( $A$ and $\beta$ ), which also have a considerable impact on salmon NPV (Fig. 5a). The interest rate has stronger effects on herring fisheries than on salmon fisheries (Fig. 5b), probably due to its larger scale of fisheries with high profit. For both fisheries, the increasing interest rate appears a common situation with a decrease in long-term stock and NPV due to the increase in harvest in the

(a) Salmon

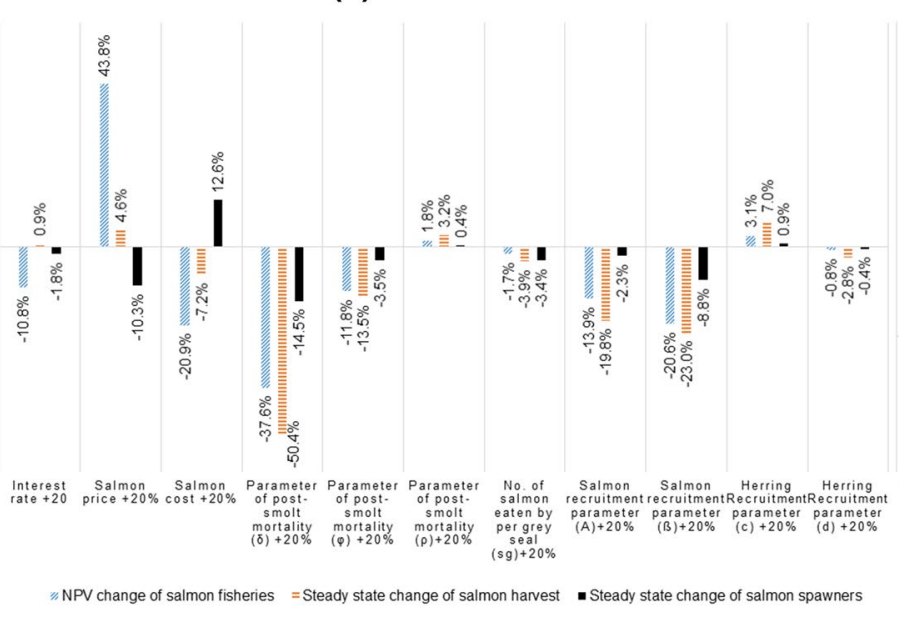

(b) Herring

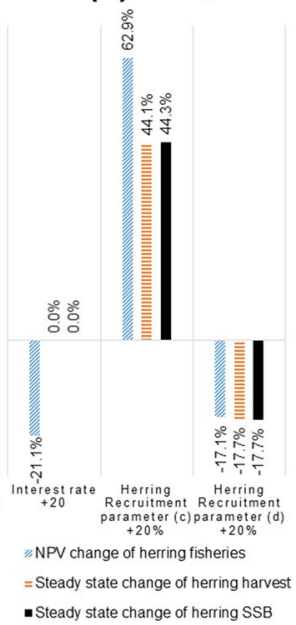

Fig. 5 Sensitivity analysis of the Baseline scenario: percentage change of (a) salmon and (b) herring in net present value (NPV), steady state of harvest, and steady state of population due to the changes in the key economic and biological parameters 


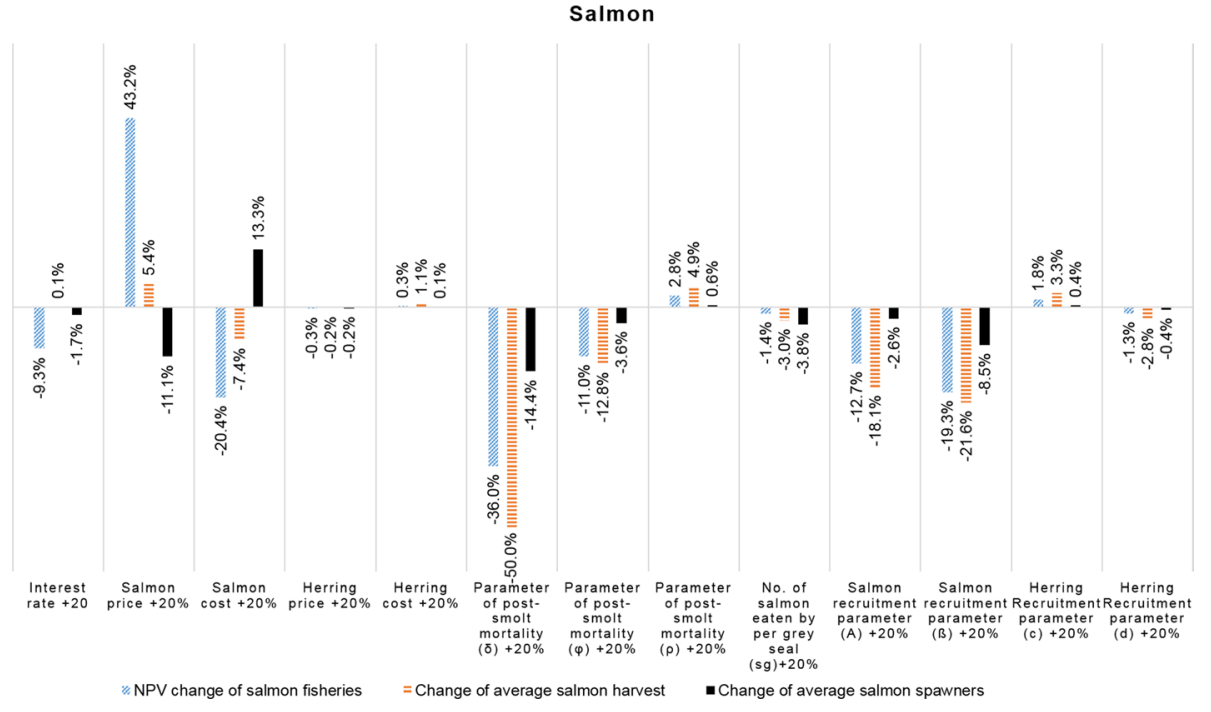

Fig. 6 Sensitivity analysis of scenario $S_{M E Y}-H_{M E Y}-1$ : percentage change of salmon net present value (NPV), average harvest, and average population due to the changes in the key economic and biological parameters

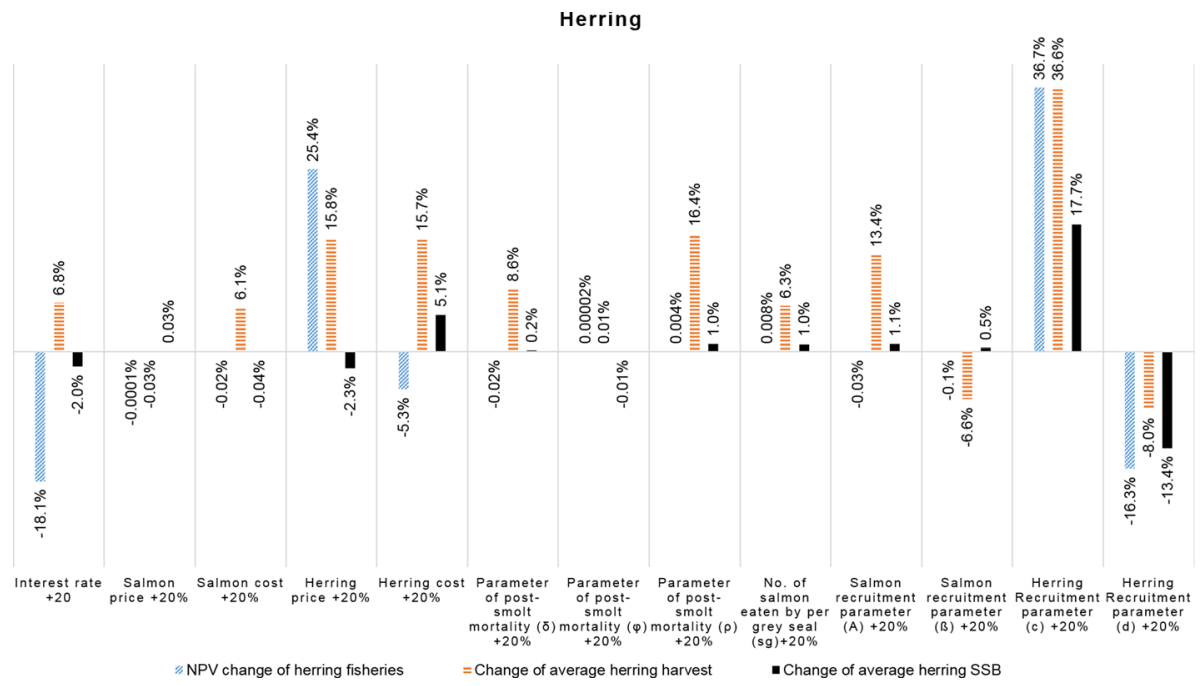

Fig. 7 Sensitivity analysis of scenario $\mathrm{S}_{\mathrm{MEY}}-\mathrm{H}_{\mathrm{MEY}}-1$ : percentage change of herring net present value (NPV), average harvest, and average population due to the changes in the key economic and biological parameters

short-term. Herring recruitment is an important factor that influences herring both on SSB and on fisheries, while the indirect effects on salmon spawners and fisheries represent only a small percentage (Fig. 5).

Unlike the analysis for the Baseline scenario, no steady states exist in scenario $\mathrm{S}_{\mathrm{MEY}}-\mathrm{H}_{\mathrm{MEY}}-1$. Therefore, we used the average value from year 36 to year 40 to compare 


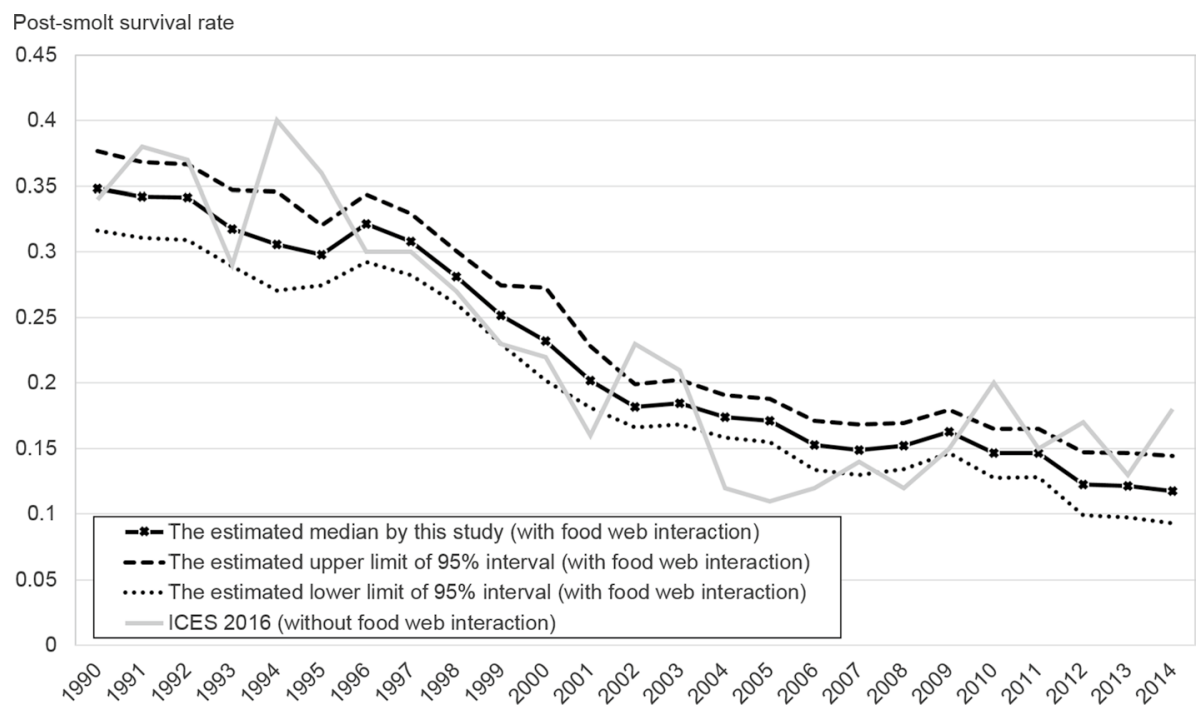

Fig. 8 Post-smolt survival rate estimated with food web interaction and its comparison with the historical value estimated by ICES (2016)

the results on population and harvest. Sensitivity analysis for salmon NPV, harvest and spawners population in scenario $\mathrm{S}_{\mathrm{MEY}^{-}} \mathrm{H}_{\mathrm{MEY}^{-1}}$ (Fig. 6) has a similar trend as the sensitivity results in scenario Baseline (Fig. 5a). Figures 6 and 7 show that indirect effects of the biological or economic drivers from the other fisheries are minor. The average harvest of herring is the most sensitive variable regarding salmon biological drivers, but the indirect

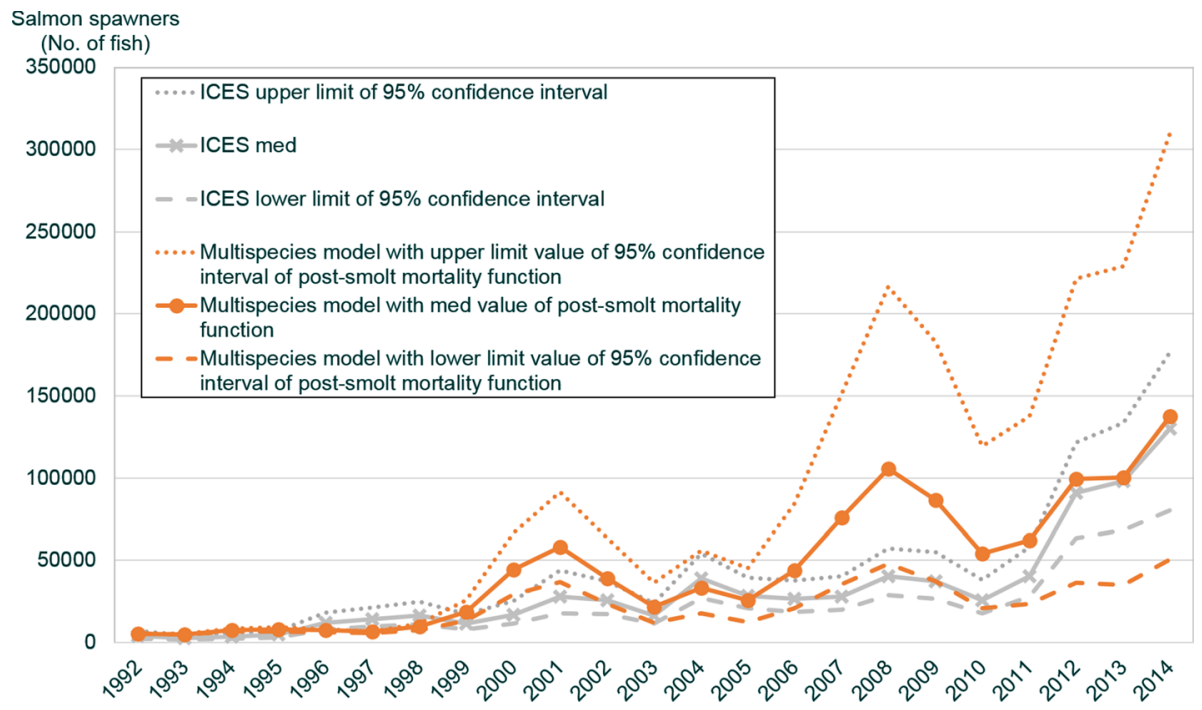

Fig. 9 Estimated salmon spawners in the river from the multispecies model and single species estimation from ICES (2015b) 


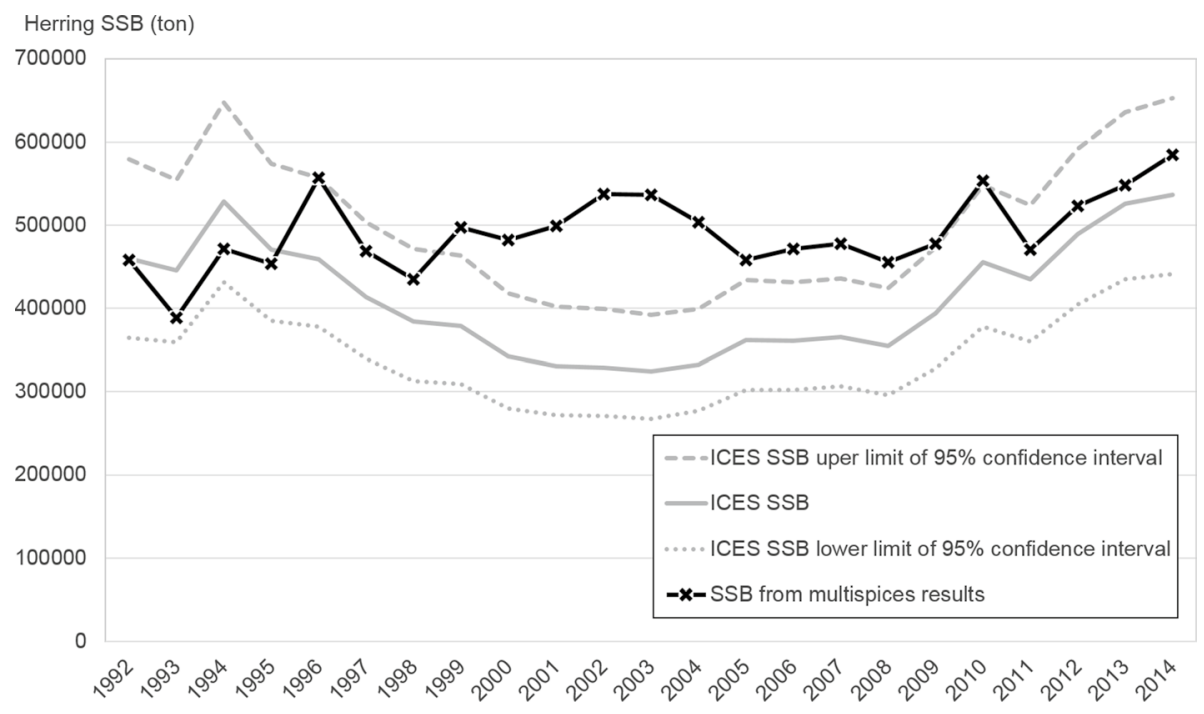

Fig. 10 Estimated spawning stock biomass (SSB) of herring from the multispecies model and single species estimation from ICES (2015a)

effects on herring NPV are less than $1 \%$, as the harvest change does not happen in the first few years. Herring recruitment, price, cost and interest rate are still the main drivers that affect herring SSB, harvest and NPV (Fig. 7).

Overall, Figs. 5, 6, 7 show that some of the results are sensitive to the parameters (change roughly 40-60\%). However, sensitivity analysis of the similar parameters (e.g., salmon price to NPV, post-smolt survival to NPV and catch) in the single species salmon model (Holma et al. 2014) demonstrate much higher volatility (over 100\%). Compared to the sensitivity analysis of the single species model in general, the results in our multispecies model are less sensitive to parameter change and we consider them acceptable.

\section{Discussion and Conclusion}

This paper developed a multispecies bio-economic model that includes the food web relations among grey seals, Atlantic salmon, and herring in the Baltic Sea by extending and combining the age-structured single species models of each species. The study examined the potential influences on salmon fisheries and stocks from the other two species. The study also explores the trade-off between salmon and herring fisheries and compares different multispecies management scenarios.

Our study shows that seals and herring, along with the indirect effects of herring fisheries, affect both salmon fisheries and the salmon population. Salmon fisheries are clearly more vulnerable under the studied management policies, as the effort and harvest are the first to be affected by a salmon population change at sea. However, if fisheries could strictly follow the chosen management policies, the salmon spawning population could remain relatively stable. The impacts of the growing seal population on salmon fisheries and the salmon population are stronger than the impacts of the herring population and fisheries. 
This result also matches the claim of the profit loss from the salmon fisheries due to the increasing population of grey seals (Holma et al. 2014). If low herring SSB and high seal population happen coincidentally, the salmon population is likely to decrease to a low level, with the consequence of eliminating the profits in the harvest in some years. The herring population is only slightly influenced by grey seals; therefore, whether the seal population is constant or increases, it has a negligible effect on herring population and fisheries.

As described, a growing seal population's influence on herring is likely small, and its influence is likely considerable on salmon; however, further biological studies are required to support the predictability of these relations. Current biological studies concluded that grey seal consumption only has a small effect on herring stocks (Gardmark et al. 2012; ICES 2015a), but the conclusion was made based on the seal population before 2014 (fewer than 32,019 individuals). Another modeling study, Costalago et al. (2019), also concluded that grey seals have little impact on herring stock even with high seal population and climate change. However, the study focused on the herring population in the south part of the Baltic Sea. Therefore, their conclusion is not directly comparable to our results. Rather, their results actually pointed out possible uncertainties that the mortality rate of herring from seals is likely decreasing with warming climate scenarios and increasing with high seal population. Climate change may also have a counter influence on the seal population, e.g., a potential decrease in the seal population (Kauhala and Kurkilahti 2020), which was not simulated in this study. Also, climate change may impact salmon's post-smolt mortality or parr density (Jokikokko et al. 2016; Jutila et al. 2005, 2006). These increase the potential uncertainty of our results, but also provide suggestions for further research, where the model can be extended.

Another caveat of this study is that the post-smolt mortality function was also only estimated based on seal population data indicating fewer than 32,019 individuals. It is also questionable if the revealed negative correlation between the observed increasing trend in seal abundance vs. the decreasing trend in post-smolt mortality is due to the causal relation (predation) between grey seals and salmon post-smolts (Mäntyniemi et al. 2012). In addition to seal-herring and seal-salmon relations, there are other uncertainties. For example, we used herring SSB rather than herring recruitment at age $0+$ to represent food resources for post-smolts. This may increase the uncertainty of salmon-herring relation. In addition, for the grey seal predation rate during the spawning migration, grey seals can catch salmon from fish nets or nature in the Gulf of Bothnia (Lundström et al. 2010; Suuronen and Lehtonen 2012), but no study specifies the proportion of these two sources of salmon for seal diet. Therefore, our model may overestimate the mortality impacts of grey seals in the Gulf of Bothnia on the salmon homing population. Although the sensitivity analysis in Sect. 4.4 provides justice for some robustness of the model, our modeling approach assumes certain relatively mechanistic intraspecies interactions and ignores numerous other potential interactions, environmental drivers and wider food web interactions, which also may affect, either separately or in concert with intraspecies interactions, the population dynamics of the studied species (e.g., Cardinale et al. (2009); Friedland et al. (2017)).

Despite the uncertainties and insufficiencies of the model, our model and the results provide some useful insights into management approaches. It reveals a benefit that the model can evaluate the performance of different fisheries with identical or different management strategies simultaneously. In the comparison of multispecies management scenarios, the results show the most profitable scenario and the trade-off between herring and salmon fisheries. Our results also indicate that the performance of salmon fisheries may be influenced by the condition of herring fisheries, which implies the importance of multispecies 
management for the species that has a lower population and smaller scale of profit for fisheries.

Uncertainty is a common issue in the ecosystem model, but the ecosystem model still helpful in providing ecosystem information and ecosystem thinking (Marasco et al. 2007). Our model provides information about the possible dynamics of the population and economic variables in the case involving the studied food web relations. This study is the first step to show how a multispecies bio-economic model that includes a migratory fish can be developed. The model can be further extended to include climate factors and recreational fisheries in rivers. The model could also serve as input into other multispecies or ecosystem models for the Baltic Sea to provide more comprehensive information for ecosystembased management in the Baltic regions.

\section{Note}

1. Most of the parameter or initial values used in this study are the historical value in the year 2014, except for those with further explanation.

2. Seal-safe gears are the gears that were designed to prevent seals to damage the salmon that have been caught in the trap net. The traditional gear (traditional trap net) can have more than $50 \%$ caught salmon that are damaged by seals. By contrast, seal-safe gear, called a pontoon trap net, can lower such damaged salmon to 1\% (Holma et al. 2014).

3. The MathWorks Inc.

4. Based on ICES (2017a), the limit on fishing mortality for herring in the Gulf of Bothnia under the precautionary approach is 0.29 .

\section{Appendix 1. Population Dynamic}

\section{Grey Seal Population Model}

$$
\begin{gathered}
N_{a, t+1}^{g}=S U R_{a-1, t}^{g} \cdot N_{a-1, t}^{g}, \text { for } \mathrm{a}=2 \text { to } 46 \\
N_{1, t+1}^{g}=\sum_{a=1}^{46} F E C_{a}^{g} \cdot N_{a, t}^{g} \\
N_{t}^{g}=\sum_{a=1}^{46} N_{a, t}^{g} \cdot \mu \\
N m a_{t}^{g}=\sum_{a=6}^{46} N_{a, t}^{g} \cdot \mu
\end{gathered}
$$

Equations (20) and (21) are the population dynamics of grey seals at age classes 2-46 and for age 1 respectively. Based on (20) and (21), Eq. (22) is the total number of grey seals in year $t$ and Eq. (23) is the total adult number. A parameter $\mu$ exists in (22) and (23) to magnify the counted numbers in the grey seal survey due to the possibility of unobserved numbers (Holma et al. 2014).

For the initial population of each age class, $N_{a, 1}^{g}$, we divided the grey seal numbers, 22,547 individuals, counted in the Northern Baltic Sea in 2013 (HELCOM SEAL Expert 
Table 6 The values of age-specific parameters and the equation structure of age-specific variables for the grey seal population model

\begin{tabular}{llll}
\hline $\boldsymbol{a}$ & $\boldsymbol{f} \boldsymbol{e}_{\boldsymbol{a}}^{g}$ & $\boldsymbol{s u _ { a }}$ & $\begin{array}{l}\text { Survival rate }(\boldsymbol{S U R}) \text { and fecun- } \\
\text { dity per capita }(\boldsymbol{F E C})\end{array}$ \\
\hline Age classes & Fecundity & $\begin{array}{c}\text { Survival coefficient of } \\
\text { grey seals }\end{array}$ & \\
1 & - & 0.7 & $F E C_{a}^{g}=r s^{g} \cdot f e_{a}^{g} \cdot s u_{a}$ \\
2 & - & 0.83 & $S U R_{1}^{g}=\left(1-\left(\frac{\sum_{a=1}^{46} N_{a . t}^{g}}{K \cdot N o r}\right)^{\theta} \cdot s u_{1}\right)$ \\
$3-4$ & - & & $S U R_{a-1}^{g}=s u_{a-1}$ \\
5 & - & 0.83 & \\
6 & 0.375 & 0.95 & \\
$7-46$ & 0.75 & 0.95 & \\
\hline
\end{tabular}

Reference: Holma et al. (2014)

Group 2015) into 46 age classes with the stable age distribution proportion from Holma et al. (2014). The other components of the population model, parameter values, and the references can be seen in Tables 6 and 7. The carrying capacity for survival rate at age 1 $\left(S U R_{1}^{g}\right)$ in Table 6 uses $K \cdot$ Nor, where parameter $K$ is the carrying capacity of the entire Baltic Sea, and Nor is the proportion of the grey seal population in the Northern Baltic Sea to the total population of the entire Baltic Sea. This parameter scales down the carrying capacity of the entire Baltic Sea to our study area. We also estimate the proportion of grey seals in Finland within the study areas (NorFin) and the proportion in the Gulf of Bothnia (NorBo) for later used in the salmon and herring population model. The values of these proportions are in Table 7.

\section{Herring Population Model}

$$
\begin{gathered}
N_{a, t+1}^{h}=S U R_{a-1, t}^{h} \cdot N_{a-1, t}^{h}, \text { for } a=2 \text { to } 9 \\
S U R_{a, t}^{h}=e^{\left(-M N^{h}-o_{a}^{h} \cdot F_{t}^{h}\right)}-M G_{t}^{h} \\
M G_{t}^{h}=\frac{h g_{a}^{h} \cdot\left(N_{t}^{g} \cdot N o r B o\right)}{N_{a, t}^{\mathrm{h}}}
\end{gathered}
$$

Equation (24) is the population dynamic by age for the age classes above 2, and Eq. (25) shows the components of the survival rate in Eq. (24). The survival rate in Eq. (25) includes a component, $e^{\left(-M N^{h}-o_{a}^{h} \cdot F_{t}^{h}\right)}$, based on ICES (2013b) and an extra component that considers seal predation. In equation (25), $M N^{h}$ is the natural motility of herring, which is identical at all ages. The fishing mortality rates for each age are $o_{a}^{h} \cdot F_{t}^{h}$, which consists of a fishing mortality rate, $F_{t}^{h}$, and an age selection parameter, $o_{a}^{h}$. The survival rate for herring can be fixed or change over time, depending on the assumption of $F_{t}^{h}$ in the scenarios (Table 9). In Eq. (26), $M G_{t}^{h}$ and $h g_{a}^{h} \cdot\left(N_{t}^{g} \cdot N o r B o\right)$ are the rate and number, respectively, of herring eaten by grey seals from the Gulf of Bothnia. The composition of $N_{t}^{g}$ and NorBo can be found in Eq. (22) 


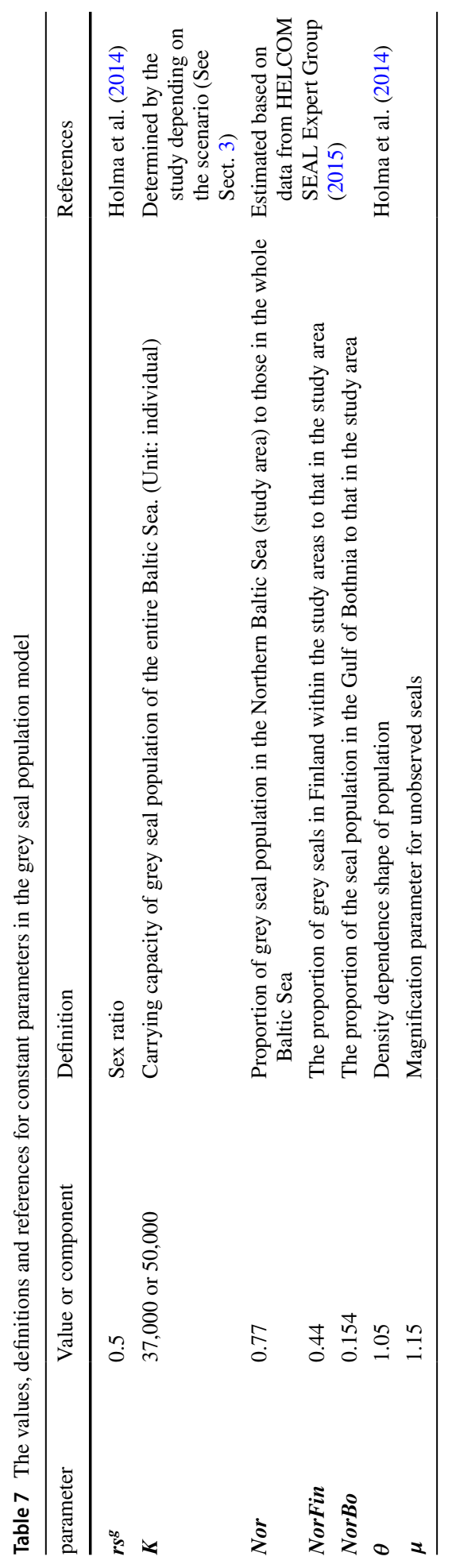


and Table 7 ; and $h g_{a}^{h}$ is the number of the herring eaten by per grey seal per year, which has been explained in Sect. 2.2.3.

The recruitment of herring is written as follows:

$$
N_{1, t+1}^{h}=S S B_{t}^{h} \cdot\left(\mathrm{c} \cdot e^{-d \cdot S S B_{t}^{h}}+\frac{\sigma}{2}\right),
$$

which was from Nieminen et al. (2012) and referred to ICES (2013b) to use half the of variance $\left(\frac{\sigma}{2}\right)$ as the normal distribution error for model fitting. The variable $S S B_{t}^{h}$ in Eq. (28) was based on Kulmala et al. (2007), with a new component $\left(M G M_{t}^{h}\right)$ to remove the amount of herring eaten by grey seals:

$$
\begin{gathered}
S S B_{t}^{h}=\sum_{a=1}^{9} A W_{a}^{h} \cdot\left(N_{a, t}^{h} \cdot \operatorname{SURM}_{a, t}^{h}\right) \cdot M A_{a}^{h}-M G M_{t}^{h} \\
M G M_{t}^{h}=\sum_{a=1}^{9} A W_{a}^{h} \cdot h g_{a}^{h} \cdot\left(N_{t}^{g} \cdot N o r B o\right) \cdot M A_{a}^{h} \\
\operatorname{SURM}_{a, t}^{h}=e^{\left(-0.33 \cdot M N^{h}-0.15 \cdot \cdot_{a}^{h} \cdot F_{t}^{h}\right)}
\end{gathered}
$$

In Eqs. (28) and (29), $A W_{(a)}^{h}$ means average weight per fish by age; $M A_{a}^{h}$ is the mature rate by age. In Eq. (29), $h g_{a}^{h} \cdot\left(N_{t}^{g} \cdot N o r B o\right)$ has the same meaning as that in Eqs. (26). Notice that Eq. (28) uses the survival rate before spawning $\left(S U R M_{a, t}^{h}\right)$ rather than the survival rate for next year $\left(S U R_{a, t}^{h}\right)$ in Eq. (25). Equation (30) implies that some of the herring die naturally or by fishing after giving birth, so $S U R M_{a, t}^{h}$ is higher than $S U R_{a, t}^{h}$ in the same year. The parameters 0.33 and 0.15 were taken from ICES (2013b). Tables 8 and 9 show the values, definitions and references for the parameters in this study.

\section{Salmon Population Model}

$$
\begin{gathered}
N_{a, t+1}^{\mathrm{s}}=S U R_{a-1, t}^{\mathrm{s}} \cdot N_{a-1, t}^{\mathrm{s}}, \text { for } \mathrm{a}=2 \text { to } 10 \\
N_{1, t+1}^{\mathrm{s}}=\sum_{a=1}^{10} F E C_{a, t}^{s} \cdot N_{a, t}^{s}
\end{gathered}
$$

Equation (31) is the population dynamics of salmon from age 2 to age 10 . SUR 5 has been explained in Sect. 2.2.2; survival rate at age 1-4 (SUR $)$ and age 6 to $9\left(S U R_{6}^{s}\right.$ to 9 ) were based on Holma et al. (2014), Michielsens et al. (2008), and Kulmala et al. (2008). The population density is controlled by the survival rate of age 4, which affects the smolt population from the river at age 5. $N_{a=6 \text { to } 10, t+1}^{\mathrm{s}}$ is the adult numbers that are feeding at sea. The mature homing population is $N m a_{t}^{s}$ and the homing population that arrives the river successfully for spawning is $N m a_{t}^{\text {spawn }}$, written as follows:

$$
\begin{gathered}
N m a_{t}^{s}=\sum_{a=6}^{10} h r_{a} \cdot N_{a, t}^{s} \\
N m a_{t}^{s p a w n}=\sum_{a=6}^{10} h r_{a} \cdot\left(e^{-q_{a}^{s} \cdot E_{t}^{s}-\left(\frac{5}{12}\right) \cdot M N^{s}+\operatorname{Ln}\left(1-M G_{t}^{s}\right)}\right) \cdot N_{a, t}^{s}
\end{gathered}
$$




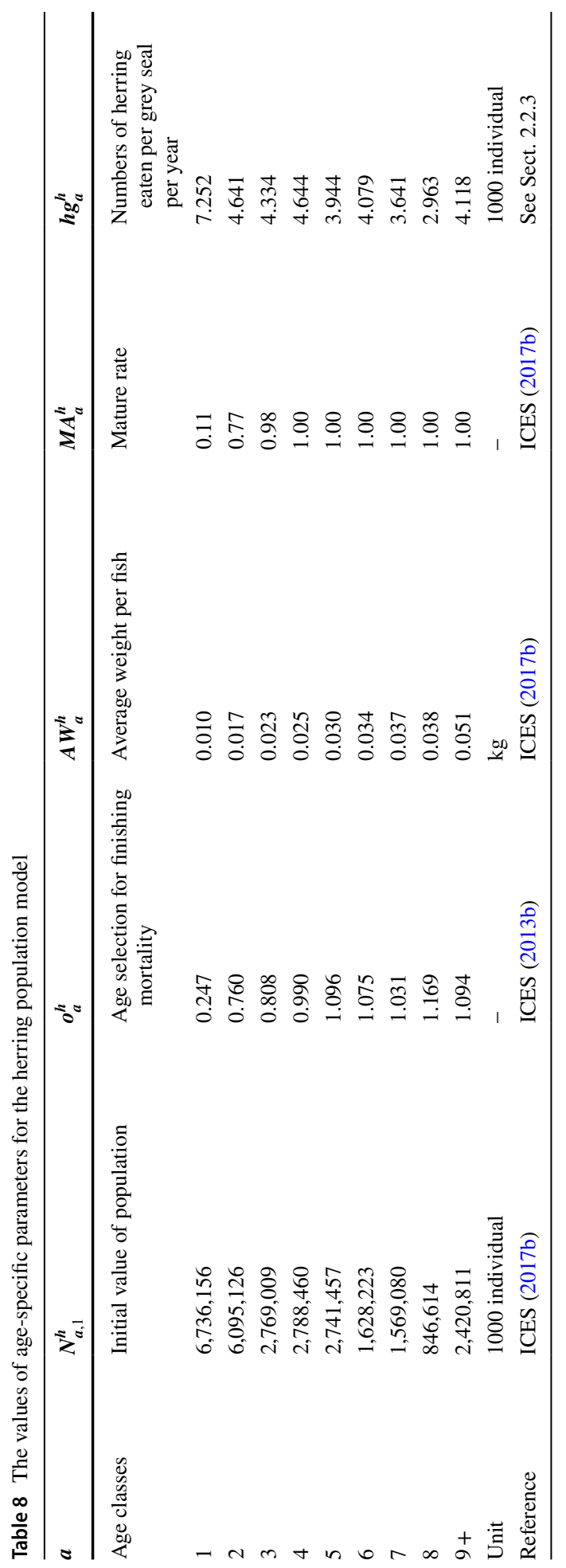


Table 9 The values, definitions and references of constant parameters for herring population model

\begin{tabular}{|c|c|c|c|}
\hline parameter & Value & Definition & Reference \\
\hline$M N^{h}$ & 0.15 & Natural mortality rate & ICES (2017b) \\
\hline$F_{t}^{h}$ & $\begin{array}{l}0.2 \text { (level in 2014) } \\
0.25 \\
\text { Others: Optimize in the model }\end{array}$ & Fishing mortality & $\begin{array}{l}\text { Determined by the study in } \\
\text { different scenarios (See } \\
\text { explanation in Sect. 3) }\end{array}$ \\
\hline c & 19.4 & Parameter for recruitment & ICES (2013b) \\
\hline$d$ & 0.00000046 & Parameter for recruitment & \\
\hline$\sigma$ & 7.919 & $\begin{array}{l}\text { Variance of the stock-recruit } \\
\text { fitting }\end{array}$ & \\
\hline
\end{tabular}

Equation (32) is the population dynamics of salmon from age 1. Equation (32) and its component, $F E C_{a, t}^{s}$, have been explained in Sect. 2.2.1. The other components of the model, as well as definitions and values of the parameters, can be seen in Table 10 and Table 11.

\section{Equations and Parameters Related to Economic Models}

The profit function, harvest function, and damage function have been described in Sect. 2.3. In Table 12, we list the values of the parameters and the equations that were not displayed completely but were mentioned in Sect. 2.3 and Sect. 3 .

\section{Appendix 2. Retrospective Simulation}

To compare our multispecies bio-economic model with existing single species estimation, we also retrospectively simulated the population with the historical values of the parameters. In this historical simulation, we collected the values of the coastal fishing effort of salmon $\left(E^{s}\right)$, the homing rate of salmon $\left(h r_{a}\right)$, and M74 mortality ( $m 74$; see the explanation of M74 from Mikkonen et al. (2011)) from 1992-2014 from ICES (2015b). The other salmon parameter values were from Holma et al. (2014). The initial salmon population $\left(N_{a, 1}^{s}\right)$ in 1992 was estimated based on the historical parameter values mentioned above, the smolt and post-smolt mortality data from ICES (2016), and the population model developed in this study. The grey seal population from 1992-2014 was obtained from counting data (HELCOM SEAL Expert Group 2015). For herring, we took the initial population $\left(N_{a, 1}^{h}\right)$ in 1992, along with fishing mortality $\left(F^{h}\right)$, average weight by ages $\left(A W_{a}^{h}\right)$, and mature rate by ages $\left(M A_{a}^{h}\right)$ between 1992 and 2014 from ICES (2015a). For the rest of the parameters, historical values were not accessible in the open reports and databases; therefore, we chose to use their latest values (listed in "Appendix 1").

Figure 8 shows that the post-smolt survival rate with consideration of food web interaction follows the trend of the post-smolt survival estimated from ICES, although the variation does not completely match. When including the post-smolt mortality function with consideration of food web interaction, the retrospective simulation of the multispecies model shows an agreement trend of salmon spawners between our multispecies estimation and the singles species estimation from ICES (Fig. 9). The level of herring SSB from the multispecies modeling, however, is higher than in the ICES estimation (Fig. 10). The 


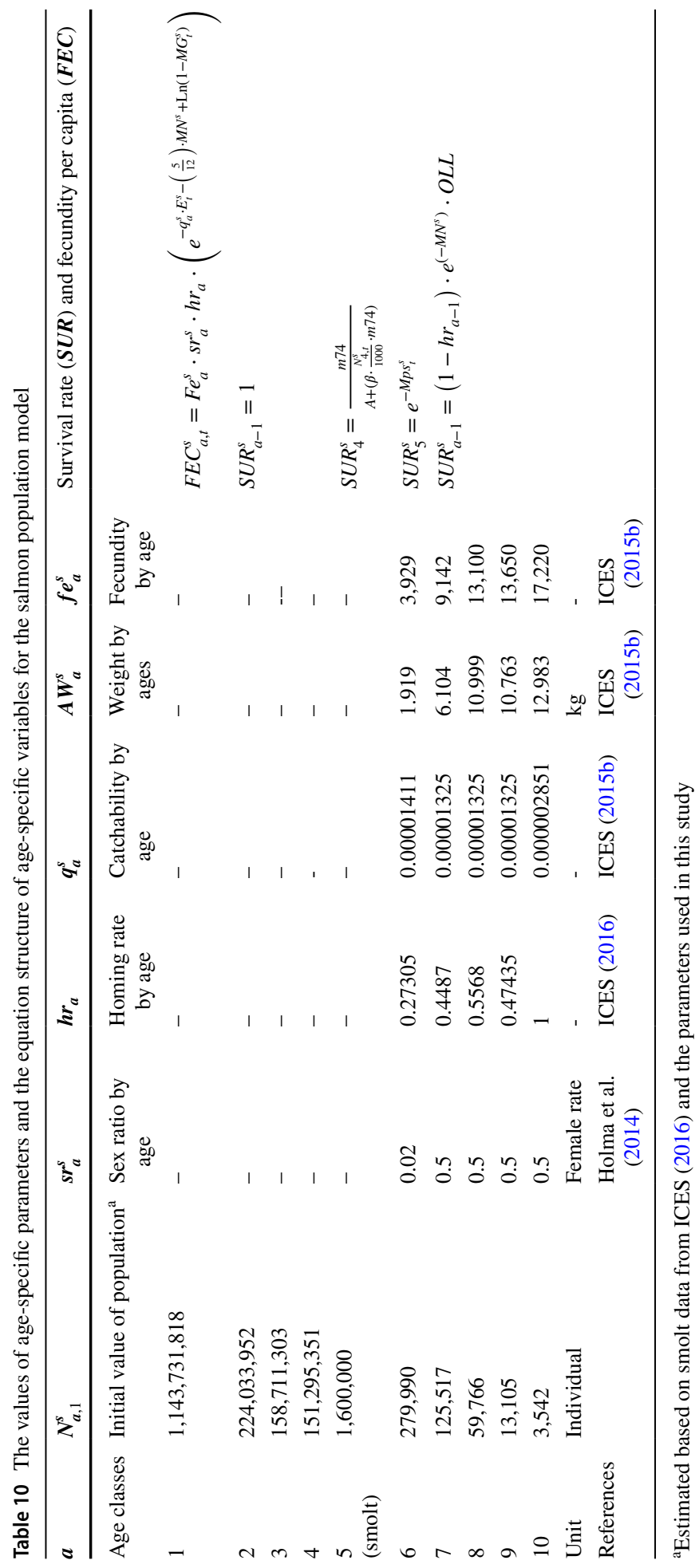




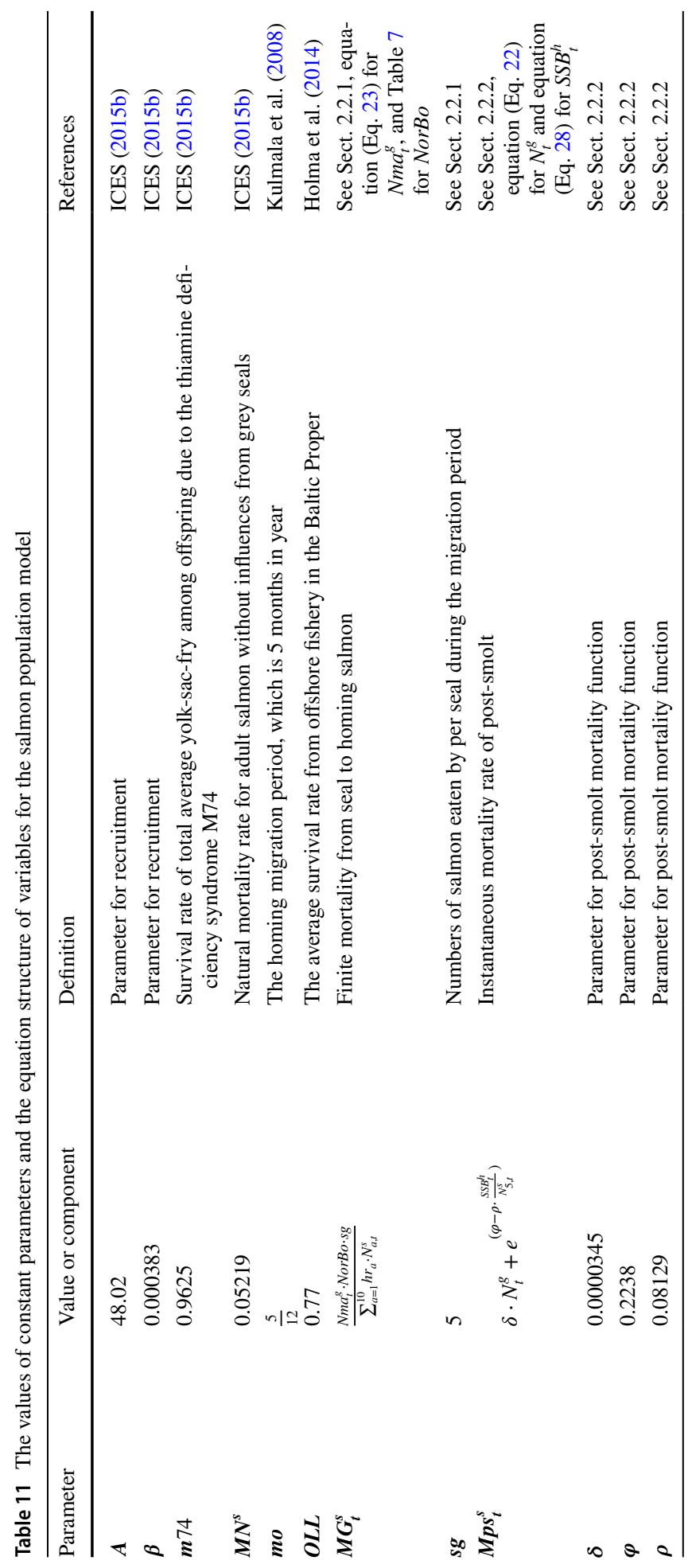




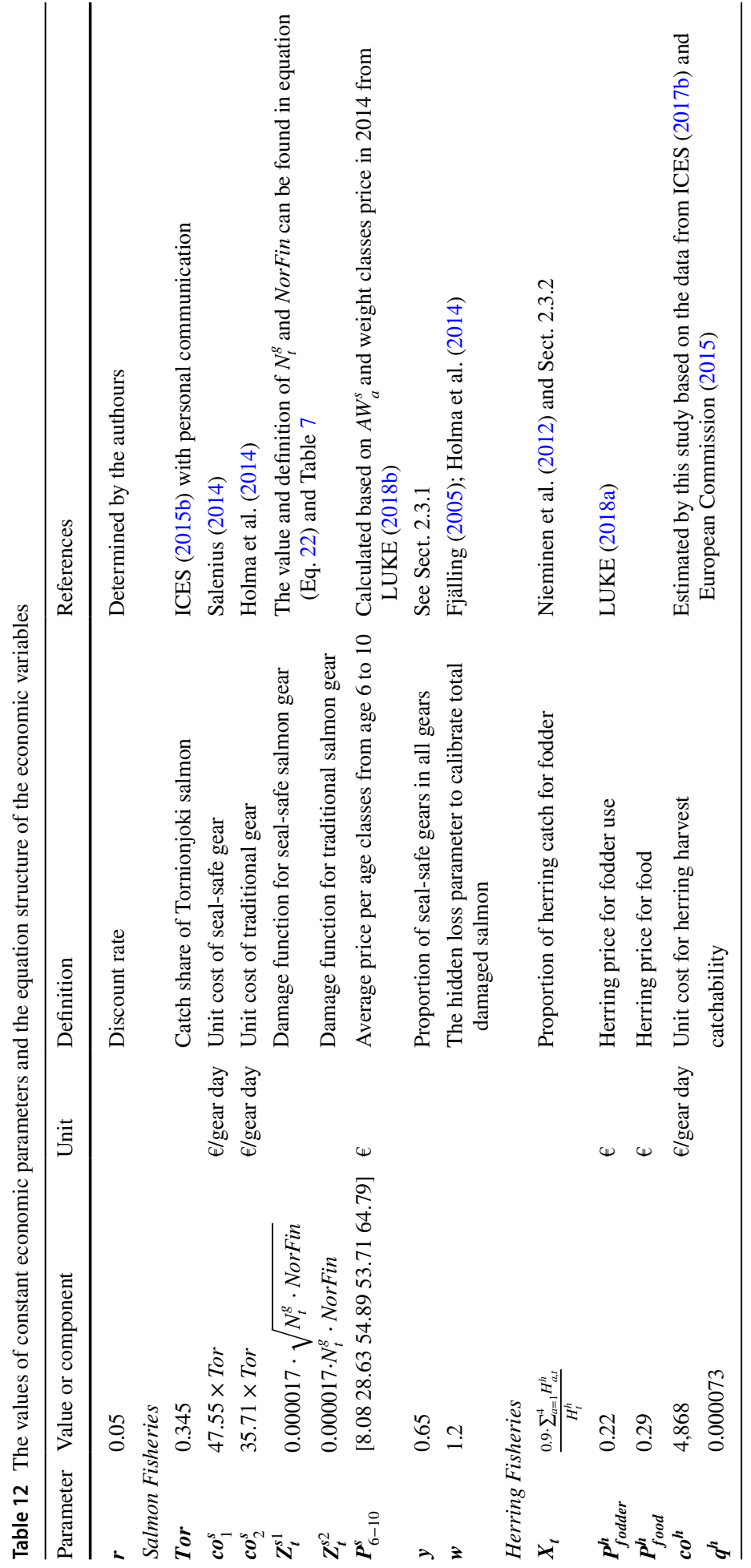


Fig. 11 The ranks of the Bayesian p-values of the predicted value (logarithm value of natural mortality of post-smolt salmon) show a close uniform distribution. The mean of Bayesian $P$-value is 0.494 , representing the proportion of the replicated data from the model larger than the actual data (Lunn et al. 2012)

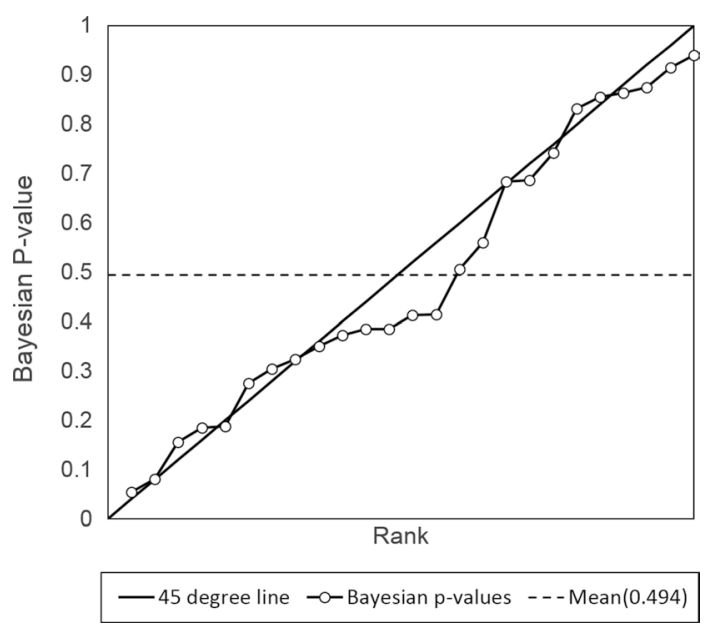

resulting differences between the multispecies model from this study and the single species assessments are primarily due to the unavailability of the yearly historical value of some parameters (e.g., recruitment parameters).

\section{Appendix 3. Fitness Check of the Model for Post-Smolt Mortality Function from Bayesian Inference}

The parameter of the post-smolt mortality function was estimated by the Bayesian inference with OpenBUGS software. The estimation was based on the logit-transformation of the data; thus, the following goodness-of-fit check of the model regards the logarithm value before transforming the data back. Figure 11 shows the posterior predictive checks regarding the logarithm value of the natural mortality of post-smolt salmon (predicted value). The mean (0.494), the standard deviation (SD) (0.281), and the rank distribution of the Bayesian P-values are close to a perfect uniform distribution (mean $=0.5, \mathrm{SD}=0.288$ ) (Breheny et al. 2018). Figure 12 shows that the Bayesian $P$-value of the predicted value is independent of the explanatory variable. The residual from the model is also independent of the predicted value and does not show as an explicit outlier (Fig. 13). Figure 14 presents the graphical posterior predictive check Bayesian P-value for the sums of the squares of the residual, which is 0.543 . All these figures indicate that the model adequately fits the data (Kéry 2010; Lunn et al. 2012). 

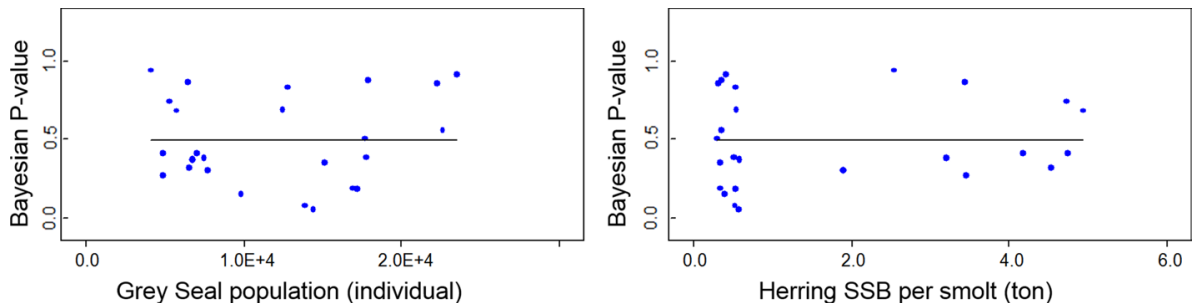

Fig. 12 The independent relations of the Bayesian p-values of the predicted value to the explanatory variable

Fig. 13 The independent relation between the residual and predicted values

Fig. 14 Graphical posterior predictive check performed by plotting the sum of the squares (SSQ) of the residual for the replicated value from model and actual data from input. The Bayesian $P$-value for SSQ is 0.543 (proportion of plot above the 1:1 line) (Kéry 2010)
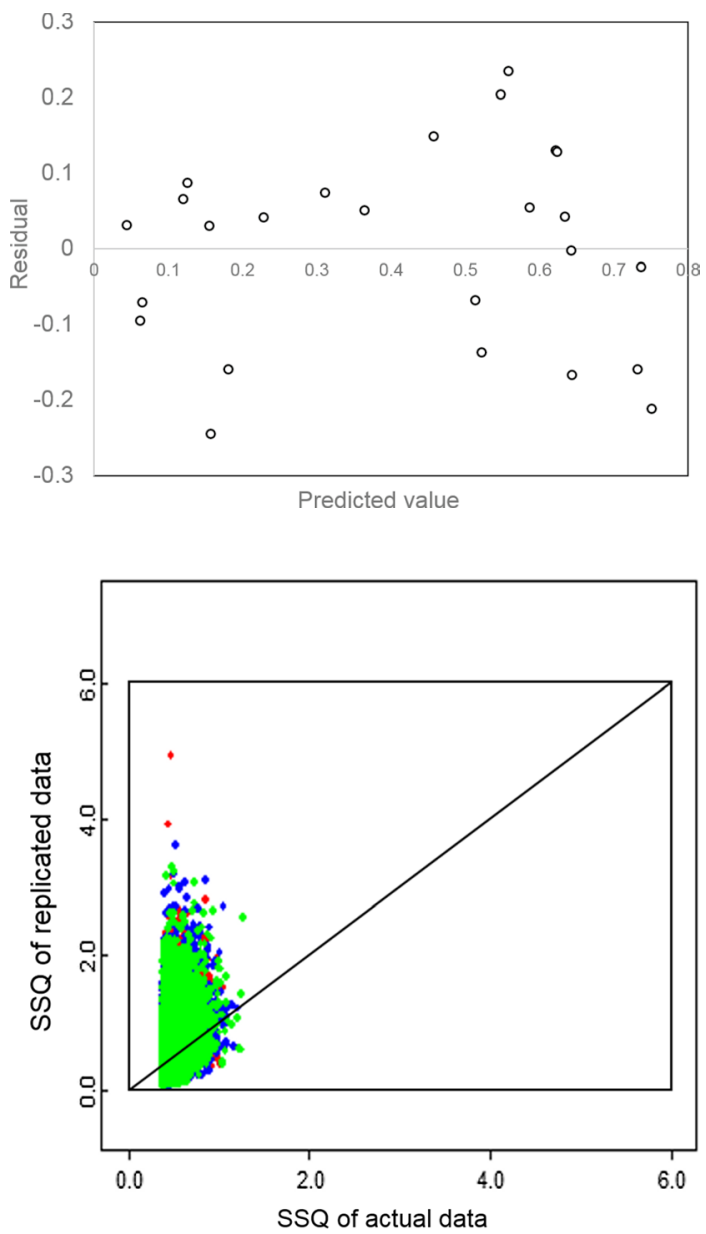
Acknowledgements We would like to thank Maija Holma for help in understanding the model from Holma et al. (2014), Emmi Nieminen for help in understanding the model from Nieminen et al. (2012), and Samu Mäntyniemi for help in understanding and properly using the Bayesian model from Mäntyniemi et al. (2012). We would also like to thank Henni Pulkkinen for providing data and giving advice. Authors acknowledge funding from project MARmaED. The MARmaED project has received funding from the European Union's Horizon 2020 research and innovation program under the Marie Skłodowska-Curie grant agreement No 675997. The results of this article reflect only the author's view, and the Commission is not responsible for any use that may be made of the information it contains.

Funding Open access funding provided by University of Helsinki including Helsinki University Central Hospital.

Open Access This article is licensed under a Creative Commons Attribution 4.0 International License, which permits use, sharing, adaptation, distribution and reproduction in any medium or format, as long as you give appropriate credit to the original author(s) and the source, provide a link to the Creative Commons licence, and indicate if changes were made. The images or other third party material in this article are included in the article's Creative Commons licence, unless indicated otherwise in a credit line to the material. If material is not included in the article's Creative Commons licence and your intended use is not permitted by statutory regulation or exceeds the permitted use, you will need to obtain permission directly from the copyright holder. To view a copy of this licence, visit http://creativecommons.org/licenses/by/4.0/.

\section{References}

Anders G, Jonas T, Michael D et al (2020) Grey seal Halichoerus grypus recolonisation of the southern Baltic Sea, Danish Straits and Kattegat. Wildl Biol 2020(4):wlb.00711. https://doi.org/10.2981/wlb.00711

Andersen KH, Brander K, Ravn-Jonsen L (2015) Trade-offs between objectives for ecosystem management of fisheries. Ecol Appl 25(5):1390-1396. https://doi.org/10.1890/14-1209.1

Bastardie F, Vinther M, Nielsen JR (2012) Impact assessment (IA) of alternative HCRs to the current multiannual Baltic Sea plan on the bio-economy of fleets - coupling the SMS model to the FLR baltic model, working document to STECF EWG 12-02. In: Simmonds J, Jardim E (eds) Scientific, technical and economic committee for fisheries (STECF) multispecies management plans for the Baltic (STECF-12-06). Publications Office of the European Union, Luxembourg, p 36

Blenckner T, Döring R, Ebeling M et al (2011) FishSTERN: a first attempt at an ecological-economic evaluation of fishery management scenarios in the Baltic Sea region. Final report. Report, no. 6428. The Swedish Environmental Protection Agency, Stockholm, p 90

Bossier S, Palacz AP, Nielsen JR et al (2018) The Baltic Sea Atlantis: an integrated end-to-end modelling framework evaluating ecosystem-wide effects of human-induced pressures. PLoS ONE 13(7):e0199168. https://doi.org/10.1371/journal.pone.0199168

Breheny P, Stromberg A, Lambert J (2018) p-value histograms: inference and diagnostics. High-Throughput 7:23. https://doi.org/10.3390/ht7030023

Cardinale M, Möllmann C, Bartolino V et al (2009) Effect of environmental variability and spawner characteristics on the recruitment of Baltic herring Clupea harengus populations. Mar Ecol Prog Ser 388:221-234. https://doi.org/10.3354/meps08125

Clark CW (1976) Mathematical bioeconomics: the optimal management of renewable resources. Wiley, New York

Clark CW (2010) Mathematical bioeconomics: the mathematics of conservation. Wiley, Hoboken, N. J.

Conrad JM, Adu-Asamoah R (1986) Single and multispecies systems: the the Eastern Tropical Atlantic. J Environ Econ Manag 13(1):50-68. https://doi.org/10.1016/0095-0696(86)90016-1

Costalago D, Bauer B, Tomczak MT et al (2019) The necessity of a holistic approach when managing marine mammal-fisheries interactions: environment and fisheries impact are stronger than seal predation. Ambio 48(6):552-564. https://doi.org/10.1007/s13280-018-1131-y

deYoung B, Heath M, Werner F et al (2004) Challenges of modeling ocean basin ecosystems. Science 304(5676):1463-1466. https://doi.org/10.1126/science.1094858

Doyen L, Cissé A, Gourguet S et al (2013) Ecological-economic modelling for the sustainable management of biodiversity. CMS 10(4):353-364. https://doi.org/10.1007/s10287-013-0194-2

Dujardin Y, Chades I (2018) Solving multi-objective optimization problems in conservation with the reference point method. PLoS ONE 13(1):e0190748. https://doi.org/10.1371/journal.pone.0190748 
Enríquez-Andrade RR, Vaca-Rodríguez JG, (2004) Evaluating ecological tradeoffs in fisheries management: a study case for the yellowfin tuna fishery in the Eastern Pacific Ocean. Ecol Econ 48(3):303-315. https://doi.org/10.1016/j.ecolecon.2003.09.009

Commission E (2015) Scientific, technical and economic committee for fisheries (STECF) - The 2015 annual economic report on the eu fishing fleet (STECF-15-07). In: Paulrud A, Carvalho N, Borrello A et al (eds) JRC scientific and technical reports. Publications Office of the European Union, Luxembourg, p 434

European Union (2008) DIRECTIVE 2008/56/EC of the european parliament and of the council of 17 June 2008: establishing a framework for community action in the field of marine environmental policy (Marine Strategy Framework Directive). Official Journal of the European Union L 164/19

Fjälling A (2005) The estimation of hidden seal-inflicted losses in the Baltic Sea set-trap salmon fisheries. ICES J Mar Sci 62(8):1630-1635. https://doi.org/10.1016/j.icesjms.2005.02.015

Fogarty MJ (2014) The art of ecosystem-based fishery management. Can J Fish Aquat Sci 71(3):479-490. https://doi.org/10.1139/cjfas-2013-0203

Francis RC, Hixon MA, Clarke ME et al (2007) Ten Commandments for ecosystem-based fisheries scientists. Fisheries 32(5):217-233. https://doi.org/10.1577/1548-8446(2007)32[217:TCFBFS]2.0.CO;2

Friedland KD, Dannewitz J, Romakkaniemi A et al (2017) Post-smolt survival of Baltic salmon in context to changing environmental conditions and predators. ICES J Mar Sci 74(5):1344-1355. https://doi.org/ 10.1093/icesjms/fsw178

Gardmark A, Ostman O, Nielsen A et al (2012) Does predation by grey seals (Halichoerus grypus) affect Bothnian Sea herring stock estimates? ICES J Mar Sci 69(8):1448-1456. https://doi.org/10.1093/icesj ms/fss099

Hannesson R (1983) Optimal harvesting of ecologically interdependent fish species. J Environ Econ Manag 10(4):329-345. https://doi.org/10.1016/0095-0696(83)90003-7

Harding KC, Härkönen T, Helander B et al (2007) Status of Baltic grey seals: population assessment and extinction risk. NAMMCO Scientific Publications 6:33-56. https://doi.org/10.7557/3.2720

HELCOM SEAL Expert Group (2015) Helcom seal database. http://www.helcom.fi/baltic-sea-trends/datamaps/biodiversity/seals. Cited 23 Feb 2017

Holma M, Lindroos M, Oinonen S (2014) The economics of conflicting interests: Northern baltic salmon fishery adaption to grey seal abundance. Nat Resour Model 27(3):275-299. https://doi.org/10.1111/ nrm.12034

Holma M, Lindroos M, Romakkaniemi A et al (2018) Comparing economic and biological management objectives in the commercial Baltic salmon fisheries. Mar Policy 100:207-214. https://doi.org/10. 1016/j.marpol.2018.11.011

Hutniczak B (2015) Modeling heterogeneous fleet in an ecosystem based management context. Ecol Econ 120:203-214. https://doi.org/10.1016/j.ecolecon.2015.10.023

ICES (2013a) Report of the ICES advisory committee 2013. ICES Advice 2012: Book 8, p 167

ICES (2013b) Report of the inter-benchmark protocol for herring in subdivision 30 (IBP Her30). ICES CM 2013/ACOM:60, Copenhagen, p 94

ICES (2014) Stock Annex: Salmon (Salmo salar) in Subdivisions 22-31 (Baltic Sea, excluding the Gulf of Finland) and Salmon (Salmo salar) in Subdivision 32 (Gulf of Finland). ICES Stock Annex, p 47

ICES (2015a) Report of the Baltic fisheries assessment working group (WGBFAS). ICES CM 2015/ ACOM:10, Copenhagen, p 826

ICES (2015b) Report of the Baltic Salmon and trout assessment working group (WGBAST). ICES CM 2015\ACOM:08, Rostock, p 362

ICES (2016) Report of the Baltic Salmon and trout assessment working group (WGBAST). ICES CM 2016/ ACOM:09, Klaipeda, p 257

ICES (2017a) ICES Advice on fishing opportunities, catch, and effort: Herring (Clupea harengus) in subdivisions 30 and 31 (Gulf of Bothnia). ICES Advice 2017:8

ICES (2017b) Report of the Baltic fisheries assessment working group (WGBFAS). ICES CM 2017/ ACOM:11, Copenhagen, p 810

Ikonen E (2006) The role of the feeding migration and diet of Atlantic salmon (Salmo salar L.) in yolk-sackfry mortality (M74) in the Baltic Sea. Doctoral Dissertation, University of Helsinki and Finnish Game and Fisheries Research Institute

Jokikokko E, Jutila E, Kallio-Nyberg I (2016) Changes in smolt traits of Atlantic salmon (Salmo salarLinnaeus, 1758) and linkages to parr density and water temperature. J Appl Ichthyol 32(5):832-839. https://doi.org/10.1111/jai.13113

Jonsson N, Jonsson B (2003) Energy density and content of Atlantic salmon: variation among developmental stages and types of spawners. Can J Fish Aquat Sci 60:506-516 
Jutila E, Jokikokko E, Julkunen M (2005) The smolt run and postsmolt survival of Atlantic salmon, Salmo salar L., in relation to early summer water temperatures in the northern Baltic Sea. Ecol Freshw Fish 14(1):69-78. https://doi.org/10.1111/j.1600-0633.2005.00079.x

Jutila E, Jokikokko E, Julkunen M (2006) Long-term changes in the smolt size and age of Atlantic salmon, Salmo salar L., in a northern Baltic river related to parr density, growth opportunity and postsmolt survival. Ecol Freshw Fish 15(3):321-330. https://doi.org/10.1111/j.1600-0633.2006.00171.x

Kallio-Nyberg I, Saloniemi I, Jutila E et al (2011) Effect of hatchery rearing and environmental factors on the survival, growth and migration of Atlantic salmon in the Baltic Sea. Fish Res 109(2-3):285-294. https://doi.org/10.1016/j.fishres.2011.02.015

Kauhala K, Kurkilahti M (2020) Delayed effects of prey fish quality and winter temperature during the birth year on adult size and reproductive rate of Baltic grey seals. Mammal Res 65(1):117-126. https://doi. org/10.1007/s13364-019-00454-1

Kéry M (2010) Introduction to WinBUGS for ecologists: a Bayesian approach to regression, ANOVA, mixed models and related analyses. Elsevier Inc, Burlington San Diego London Amsterdam

Kulmala S, Haapasaari P, Karjalainen TP et al (2013) TEEB Nordic case: ecosystem services provided by the Baltic salmon - a regional perspective to the socio-economic benefits associated with a keystone species. In Kettunen M, Vihervaara P, Kinnunen S et al (eds) Socio-economic importance of ecosystem services in the Nordic Countries - Scoping assessment in the context of The Economics of Ecosystems and Biodiversity (TEEB). Nordic Council of Ministers, Copenhagen

Kulmala S, Laukkanen M, Michielsens C (2008) Reconciling economic and biological modeling of migratory fish stocks: optimal management of the Atlantic salmon fishery in the Baltic Sea. Ecol Econ 64(4):716-728. https://doi.org/10.1016/j.ecolecon.2007.08.002

Kulmala S, Peltomäki H, Lindroos M et al (2007) Individual transferable quotas in the Baltic Sea herring fishery: a socio-bioeconomic analysis. Fish Res 84(3):368-377. https://doi.org/10.1016/j.fishr es.2006.11.029

Kuosa H, Fleming-Lehtinen V, Lehtinen S et al (2017) A retrospective view of the development of the Gulf of Bothnia ecosystem. J Mar Syst 167:78-92. https://doi.org/10.1016/j.jmarsys.2016.11.020

Laukkanen M (2001) A bioeconomic analysis of the northern Baltic Salmon fishery: coexistence versus exclusion of competing sequential fisheries. Environ Resour Econ 18(3):293-315. https://doi.org/ 10.1023/A:1011164523802

Lindegren M, Östman Ö, Gårdmark A (2011) Interacting trophic forcing and the population dynamics of herring. Ecology 92(7):1407-1413. https://doi.org/10.1890/10-2229.1

Link JS (2002) What does ecosystem-based fisheries management mean. Fisheries 27(4):18-21

Long RD, Charles A, Stephenson RL (2015) Key principles of marine ecosystem-based management. Mar Policy 57:53-60. https://doi.org/10.1016/j.marpol.2015.01.013

LUKE (2016) Official Statistics of Finland (OSF): Catches in commercial marine fishery (1000 kg). http://statdb.luke.fi/PXWeb/pxweb/en/LUKE/LUKE__06\%20Kala\%20ja\%20riista_02\%20Rak enne\%20ja\%20tuotanto__02\%20Kaupallinen\%20kalastus\%20merella/4_meri_saalis.px/?rxid= dc711a9e-de6d-454b-82c2-74ff79a3a5e0. Cited 26 Feb 2017

LUKE (2018a) Official Statistics of Finland (OSF): Producer prices for Baltic herring (euro/kg). http:// statdb.luke.fi/PXWeb/pxweb/en/LUKE/LUKE__06\%20Kala\%20ja\%20riista__04\%20Talous_02\% 20Kalan\%20tuottajahinta/2_Silakanhinnat.px/?rxid=dc711a9e-de6d-454b-82c2-74ff79a3a5e0. Cited 2 June 2018

LUKE (2018b) Official Statistics of Finland (OSF): Producer prices for salmon (e/kg). http://statdb.luke.fi/ PXWeb/pxweb/en/LUKE/LUKE_06\%20Kala\%20ja\%20riista_04\%20Talous_02\%20Kalan\%20tuo ttajahinta/4_Lohenhinnat.px/?rxid=dc711a9e-de6d-454b-82c2-74ff79a3a5e0. Cited 2 June 2018

Lundström K, Hjerne O, Lunneryd S-G et al (2010) Understanding the diet composition of marine mammals: grey seals (Halichoerus grypus) in the Baltic Sea. ICES J Mar Sci 67(6):1230-1239. https:// doi.org/10.1093/icesjms/fsq022

Lunn D, Jackson C, Best N et al (2012) The BUGS book: a practical introduction to Bayesian analysis. Chapman \& Hall, New York

MAF, FGFRI (2014) Annual Report 2013 Finland. National data collection programme under council regulation (EC) $\mathrm{N}^{\circ} 199 / 2008$, commission regulation (EC) $\mathrm{N}^{\circ} 655 / 2008$ and commission decision $\mathrm{N}^{\circ}$ 2010/93/EU. Ministry of Agriculture and Forestry (MAF) and finnish game and fisheries research institute (FGFRI), Finland

Mäntyniemi S, Romakkaniemi A, Dannewitz J et al (2012) Both predation and feeding opportunities may explain changes in survival of Baltic salmon post-smolts. ICES J Mar Sci 69(9):1574-1579. https://doi.org/10.1093/icesjms/fss088

Marasco RJ, Goodman D, Grimes CB et al (2007) Ecosystem-based fisheries management: some practical suggestions. Can J Fish Aquat Sci 64(6):928-939. https://doi.org/10.1139/f07-062 
Michielsens CGJ, McAllister MK, Kuikka S et al (2008) Combining multiple Bayesian data analyses in a sequential framework for quantitative fisheries stock assessment. Can J Fish Aquat Sci 65(5):962974. https://doi.org/10.1139/f08-015

Michielsens CGJ, McAllister MK, Kuikka S et al (2006) A Bayesian state-space mark-recapture model to estimate exploitation rates in mixed-stock fisheries. Can J Fish Aquat Sci 63(2):321-334. https:// doi.org/10.1139/f05-215

Mikkonen J, Keinanen M, Casini M et al (2011) Relationships between fish stock changes in the Baltic Sea and the M74 syndrome, a reproductive disorder of Atlantic salmon (Salmo salar). ICES J Mar Sci 68(10):2134-2144. https://doi.org/10.1093/icesjms/fsr156

Ministry of agriculture and forestry (2007) Management plan for the finnish seal populations in the Baltic Sea. p 96

Nguyen TV (2012) Ecosystem-based fishery management: a review of concepts and ecological economic models. J Ecosyst Manag 13(2):1-14

Nielsen JR, Thunberg E, Holland DS et al (2018) Integrated ecological-economic fisheries models-evaluation, review and challenges for implementation. Fish Fish 19(1):1-29. https://doi.org/10.1111/ faf. 12232

Nieminen E, Lindroos M, Heikinheimo O (2012) Optimal bioeconomic multispecies fisheries management: a Baltic Sea case study. Mar Resour Econ 27(2):115-136. https://doi.org/10.5950/07381360-27.2.115

Paláncz B, Awange JL, Völgyesi L (2013) Pareto optimality solution of the Gauss-Helmert model. Acta Geod Geophys 48(48):293-304. https://doi.org/10.1007/s40328-013-0027-3

Patrick WS, Link JS (2015) Myths that continue to impede progress in ecosystem-based fisheries management. Fisheries 40(4):155-160. https://doi.org/10.1080/03632415.2015.1024308

Pikitch EK, Santora C, Babcock EA et al (2004) Ecosystem-based fishery management. Science 305(5682):346-347. https://doi.org/10.1126/science.1098222

Punnathanam V, Sivadurgaprasad C, Kotecha P (2016) On the performance of MATLAB's inbuilt genetic algorithm on single and multi-objective unconstrained optimization problems. Paper presented at the 2016 international conference on electrical, electronics, and optimization techniques (ICEEOT), Chennai, 3-5 March 2016

Ricker WE (1975) Computation and interpretation of biological statistics of fish populations. Department of the environment, fisheries and marine service, Ottawa

Rindorf A, Schmidt J, Bogstad B et al (2013) A framework for multispecies assessment and management: An ICES/NCM background document. Nordic Council of Ministers, Denmark

Rudstam LG, Aneer G, Hildén M (1994) Top-down control in the pelagic Baltic ecosystem. Dana 10:105-129

Salenius FR (2014) Economic consequences of fuel tax concessions removal in northern Baltic salmon fisheries. Master thesis, University of Helsinki

Salminen M (2001) Diet of post-smolt and one-sea-winter Atlantic salmon in the Bothnian Sea, Northern Baltic. J Fish Biol 58(1):16-35. https://doi.org/10.1111/j.1095-8649.2001.tb00496.x

Stenman O (2007) How does hunting grey seals (Halichoerus grypus) on Bothnian Bay spring ice influence the structure of seal and fish stocks? ICES CM 2007/ C:12, Helsinki, p 10

Suuronen P, Lehtonen E (2012) The role of salmonids in the diet of grey and ringed seals in the Bothnian Bay, northern Baltic Sea. Fish Res 125-126:283-288. https://doi.org/10.1016/j.fishres.2012.03.007

Tahvonen O (2009) Economics of harvesting age-structured fish populations. J Environ Econ Manag 58(3):281-299. https://doi.org/10.1016/j.jeem.2009.02.001

Tahvonen O, Quaas MF, Schmidt JO et al (2012) Optimal harvesting of an age-structured schooling fishery. Environ Resour Econ 54(1):21-39. https://doi.org/10.1007/s10640-012-9579-x

Vaca-Rodríguez JG, Enríquez-Andrade RR (2006) Analysis of the eastern Pacific yellowfin tuna fishery based on multiple management objectives. Ecol Model 191(2):275-290. https://doi.org/10.1016/j. ecolmodel.2005.04.025

Voss R, Quaas MF, Schmidt JO et al (2014a) Regional trade-offs from multi-species maximum sustainable yield (MMSY) management options. Mar Ecol Prog Ser 498:1-12. https://doi.org/10.3354/meps10639

Voss R, Quaas MF, Schmidt JO et al (2014b) Assessing social-ecological trade-offs to advance ecosystembased fisheries management. PLoS ONE 9(9):e107811. https://doi.org/10.1371/journal.pone.0107811

Yun SD, Hutniczak B, Abbott JK et al (2017) Ecosystem-based management and the wealth of ecosystems. Proc Natl Acad Sci 114(25):6539-6544. https://doi.org/10.1073/pnas.1617666114

Publisher's Note Springer Nature remains neutral with regard to jurisdictional claims in published maps and institutional affiliations. 